Revista Española de Antropología Americana ISSN: 0556-6533

https://doi.org/10.5209/REAA.61968

\title{
El agua en el cerro del Rayo: nueva evidencia sobre la presencia y manejo del agua en Monte Albán
}

\author{
Araceli Rojas Martínez Gracida ${ }^{1}$
}

Recibido: 30 de agosto de 2016 / Aceptado: 2 de febrero de 2017

Resumen. El presente artículo ofrece nuevos datos sobre la existencia de agua y sistemas para su control en el sitio de Monte Albán, Oaxaca. Un reciente estudio hidrológico en los Valles Centrales de Oaxaca constató la presencia de innumerables fuentes de agua, entre escurrimientos, arroyos y manantiales, que nacen y corren por el cerro hasta llegar al Río Atoyac en la base del valle. Un recorrido de superficie confirmó la existencia de estos afluentes así como el uso de tecnología para su manejo y control, como pozos, muros, presas y canales. Estos datos, junto con estudios previos del agua y las referencias a su deidad principal, Cociyo, sugieren que Monte Albán pudo ser concebido como un cerro de sustento, similar al altepetl, un lugar de culto para el dios del Rayo, principal proveedor de lluvia.

Palabras clave: Monte Albán, agua, manejo del agua, Cociyo, Oaxaca

\section{[en] Water in Cerro del Rayo: New Evidence on Water Presence and Management in Monte Albán}

\begin{abstract}
This article offers new data on the presence of water and the systems to control it in the site of Monte Albán, Oaxaca. A recent hydrological study of the Central Valleys of Oaxaca reveals numerous sources of water on the site. Among them, there are run-offs, streams, and springs that originate and flow down the hill until they reach the river Atoyac at the base of the valley. An archaeological survey confirmed the presence of these running waters as well as the use of technology for the control and management of water, such as wells, walls, dams and canals. This data, along with previous studies of the management of water and references to the main deity Cociyo, suggests that Monte Albán could have been seen as a hill of sustenance, similar to the altepetl, a place of worship to the god of Lightning, principal provider of rain.
\end{abstract}

Keywords: Monte Albán, water, water management, Cociyo, Oaxaca

Sumario. 1. Introducción. 2. El misterio de «la ciudad en el cerro sin agua». 3. Evidencias previas para el control de agua. 4. Nuevos hallazgos. 5. Monte Albán, cerro donde corre agua. 6. Últimas reflexiones sobre el simbolismo de Monte Albán como altepetl. 7. Referencias.

\footnotetext{
1 Investigadora invitada. Universidad de Erlangen, Alemania. ararojas@yahoo.com
} 


\section{Introducción}

El presente artículo tiene como objetivo ofrecer nueva evidencia arqueológica que apoya la presencia de tecnología hidráulica en el sitio de Monte Albán. Dichos datos concuerdan con investigaciones previas que dieron cuenta de sistemas para el control de agua (Caso et al. 1967; Neely 1967, 1972; Neely y O'Brien 1973; O'Brien et al. 1980; O'Brien et al. 1982; Sansores 1992). Desafortunadamente estos datos y el enfoque en la tecnología del agua en Monte Albán no han recibido la atención que merecen. Incluso la idea de Monte Albán como el «cerro sin agua» es una imagen (casi) instaurada en la historia del estudio del sitio. Ciertas menciones sobre que el cerro carece de fuentes naturales de agua y que sus terrenos sinuosos lo hacen en general un área insalubre, no apropiada para la agricultura (Blanton 1978: 36; Flannery y Marcus 1983: 81; Wolf 1959: 97), han proyectado una visión equivocada de Monte Albán. De ahí, la importancia de retomar el tema hídrico e hidráulico en el cerro y sitio.

Recientemente un estudio hidrológico de los acuíferos de los Valles Centrales reveló gráficamente la existencia de numerosos arroyos y manantiales que corren y escurren hasta llegar al río Atoyac (Duurzaam Stedelijk Waterbeheer Oaxaca 20132014) (Figura 1). Este estudio formó parte de iniciativas gubernamentales (Municipio de la Ciudad de Oaxaca 2012, 2013 y el Estado de Oaxaca 2014, 2016) y de particulares (principalmente MAP Urban Strategies 2013, 2014, 2016) que trabajan por encontrar soluciones para inundaciones y contaminación en estos arroyos. Actualmente éstos se encuentran afectados en sus cauces y contaminados por la reciente urbanización de la zona, impidiendo así su desemboque natural en el río. Asimismo, entre las metas a largo plazo de este y otros proyectos en curso, es lograr que los habitantes aledaños a fuentes de agua mejoren sus condiciones de vida con respecto al agua, es decir, que vivan con mayor seguridad evitando inundaciones y escasez de agua potable, al mismo tiempo intentando recuperar el equilibrio ecológico de la zona. En un esfuerzo multidisciplinario también se pretende detener la destrucción del patrimonio arqueológico al generar mayor educación dirigida a la protección y al enorme valor histórico de Monte Albán entre sus nuevos ocupantes.

Como parte de estos proyectos, a continuación se presentan los resultados de un reciente y breve recorrido de superficie no intrusivo en las laderas noroeste y oriente de Monte Albán ${ }^{2}$. Con especial interés se trabajó en el área oriente pues ahí, en el territorio de San Juan Chapultepec, San Martín Mexicapam y Montoya, es una de las áreas dónde se ha gestado mayor presión y crecimiento urbano hacia la zona de Monte Albán, y además porque el convenio de trabajo para estudiar la hidrología, urbanismo y arqueología de la zona se realizó entre las agencias interesadas (MAP Urban Strategies, Deltares y Arquinistas) y las autoridades de la Ciudad de Oaxaca, a quien pertenecen dichas agencias jurisdiccionalmente. Los objetivos de este recorrido fueron corroborar en campo la existencia de los arroyos que el mencionado estudio hidrológico había mostrado a partir de imágenes satelitales e información cartográfica, ubicarlos mediante GPS en coordenadas UTM, así como documentar el

\footnotetext{
Este artículo se centra en el cerro de Monte Albán sin considerar información de El Gallo y Atzompa, comúnmente también considerados parte del sitio. Los hallazgos en los tres cerros reflejan diferencias en los procesos históricos y culturales. Por ejemplo, en Atzompa la presencia de efigies de Cociyo no es tan frecuente (Pacheco Arias 2014).
} 


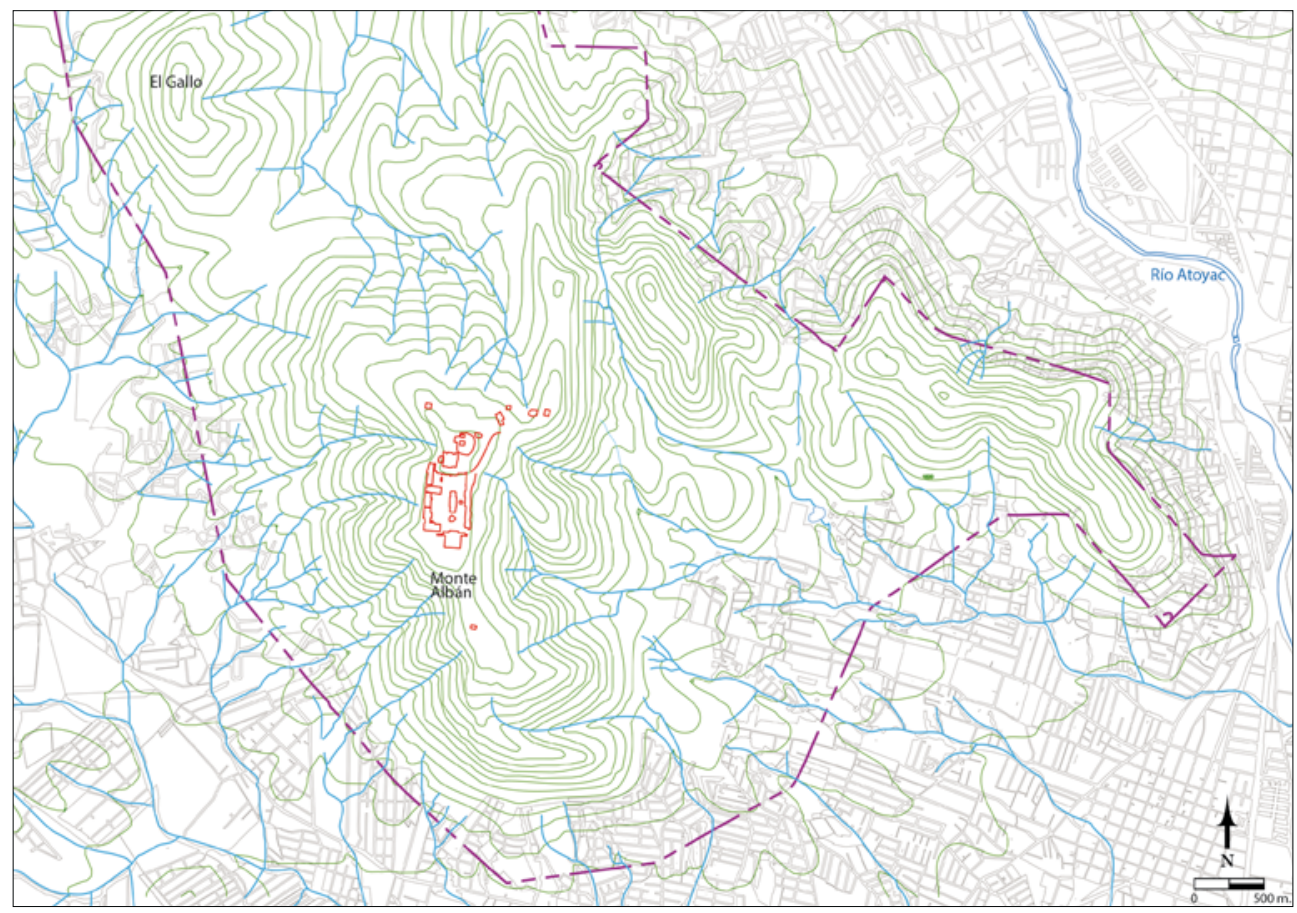

Figura 1. Arroyos y escurrimientos de agua que corren por Monte Albán (mapa cortesía de MAP Urban Strategies).

estado hídrico y de deterioro de algunos de ellos, es decir, cuánta agua corre y cuánta basura o elementos urbanos los obstruyen. Asimismo el objetivo fue identificar posibles elementos arqueológicos de tecnología hidráulica dentro o cerca de esos arroyos los cuales pudieran arrojar luz sobre los sistemas de control que se usaron en el pasado y los cuales podrían servir para proponer e inspirar las soluciones en el presente ante inundaciones y escasez de agua. Es importante mencionar que los impulsores del proyecto hídrico, urbano y de protección del patrimonio cultural, entre ellos la que suscribe, tienen especial interés por evitar la imposición de tecnologías extranjeras y en su lugar, y en lo posible, recuperar técnicas para el control del agua que funcionaron en el pasado, o mejorarlas con conocimiento moderno local o foráneo (Rojas y Beccan en prensa). Pensamos que esta metodología de trabajo es más respetuosa y sobre todo coherente dado el entorno tan rico en historia, cultura y arqueología.

Para este proyecto no fue la meta recorrer la totalidad del área dada la magnitud de dicha tarea. Se seleccionaron en específico algunos arroyos del lado oriente que tienen origen en la zona arqueológica y corren por la nueva ciudad, en las faldas del cerro. Éstos tienen además el potencial de ser saneados y transformados en sus laderas para recuperar su caudal. Entre ellos se documentó la presencia de un manantial. Del lado noroeste, con menos desarrollo urbano, se seleccionó un arroyo donde era más probable encontrar evidencia prehispánica para el control de agua de lluvia en asociación con terrazas. Dicho arroyo se encontraba cerca de previos estudios sobre el manejo de agua (Neely 1972; O’Brien et al. 1982). 
Con esta nueva información y con apoyo de evidencia de investigaciones pasadas, se sugiere que estos sistemas de control de agua tuvieron como fin el captar agua de lluvia para uso agrícola y doméstico. Los datos sugieren que en la superficie de Monte Albán corría agua y que ésta era aprovechada en áreas habitacionales y terrenos de cultivo. Dicha información es coherente con el culto a la deidad principal en el sitio, Cociyo, el Rayo, «el que provoca las lluvias».

\section{El misterio de «la ciudad en el cerro sin agua»}

Monte Albán es un ejemplo obligado en estudios de urbanismo y en el tema del surgimiento de ciudades y del estado. Su fundación en el siglo VI a.C. (entre 500 y 400 a.C., fase Danibaan) lo convirtió en el sitio más grande y complejo hasta entonces conocido en todo el territorio mesoamericano. Aun cuando algunos autores señalan que en el sitio la evidencia de áreas de especialización económica es escasa y los sistemas de abastecimiento de agua faltan, lo consideran sin duda una auténtica ciudad y el centro rector de un estado (Blanton 1978: xxiii, 107; Blanton et al. 1999: 1; Flannery y Marcus 1983: 80; Marcus 2008: 124)33. En Monte Albán se han hallado docenas de edificios monumentales, docenas de unidades residenciales y cientos de entierros y tumbas señalando gran diversidad en cuanto al material arqueológico, incluyendo joyería finamente trabajada ${ }^{4}$, vasijas efigie, murales polícromos, y la distintiva cerámica de color gris. Sus 2073 terrazas residenciales indican una ocupación de 15.000 a 30.000 habitantes en su momento de apogeo (450-600 d.C., Blanton 1978:30; ver Lind y Urcid 2009 sobre una revisión del auge de Monte Albán a través del análisis de datos provenientes de Lambityeco, señalando el momento de máxima prosperidad para ambos en la fase Xoo, 650-800 d.C.).

Los seguidores de modelos arqueológico ecológico cultural y procesual (Gándara 2012: 100-101), han descrito para los primeros siglos del sitio una visión del sitio inmersa en el militarismo y guerras sangrientas (e.g. Blanton 1978; Flannery y Marcus 1983: 81; Joyce 2010: 129; Marcus 2008). Sobre la fundación de Monte Albán se ha dicho que fue resultado de la creación de un centro neutral o una capital del tipo «disembedded», una especie de confederación entre poblados autónomos dedicada a la ofensiva y defensa de la región ante la presencia de amenaza militar por parte de enemigos externos (Blanton et al. 1999: 65). Para Richard Blanton (1978: 36) esta nueva capital neutral fue estratégicamente establecida en un terreno marginal, sinuoso y no apropiado para la agricultura, sin fuentes naturales de agua, lejos de un arroyo o río y de zonas aluviales irrigables, situación contrastada con otros sitios contemporáneos del Valle de Etla, donde ya había un largo desarrollo en sistemas hidráulicos. Dado que desde la cima de Monte Albán al río Atoyac, en la base del valle, hay aproximadamente $4 \mathrm{~km}$ de distancia (Blanton et al. 1999: 49),

\footnotetext{
En estas fuentes no queda claro cuáles son los criterios que definen a la «ciudad» o el «estado» (e.g. tamaño de población, centro político-administrativo y económico, planeación urbana y arquitectónica), usando estos dos términos indistintamente. Frecuentemente los criterios que son usados para definir una «ciudad» provienen de nociones europeas las cuales no pueden ciegamente aplicarse al contexto mesoamericano.

4 Un ejemplo de ello es la joyería encontrada en la Tumba 7 y fechada en la fase Chila (1200-1521 d.C.), lo cual es acorde con la presencia de metalurgia en Mesoamérica. Además, el gran número de tumbas demuestra que el sitio continuaba siendo usado como un sitio funerario aun cuando ya había dejado de ser un centro urbano hacía más de 600 años.
} 
el argumento lo resuelve al proyectar Monte Albán como un estado expansionista que ejerció control sobre cientos de aldeas satelitales establecidas en zonas de pie de monte, donde sí podían usar algún sistema de irrigación (sobre todo ubicados en el valle de Etla) siendo éstas las que suministraban alimento fresco e incluso agua al gran centro rector para después lograr el control y colonización de sitios más grandes y lejanos, fuera del valle de Oaxaca (de 500 a.C. a 200 d.C., fases Danibaan, Pe y Niza) (Blanton et al. 1999: 51, 94; Marcus 2008: 37, 86; Marcus y Flannery 1994: 65; Wolf 1959: 97). Para Blanton y colegas (1999: 50), al menos en los primeros siglos de existencia, el agua tuvo que ser llevada a cuestas desde el valle hasta la cima ${ }^{5}$.

Contrariamente, el mayor promotor de agua en Monte Albán es su deidad principal: Cociyo. Su nombre significa literalmente en lengua zapoteca «rayo» (Balsalobre 1953: 352; Córdova 1987: 339). Se reconoce por su máscara de nariz prolongada semejante a las fauces de una serpiente, a veces una lengua bífida, los ojos enmarcados por placas y frecuentes asociaciones con el agua y el maíz (Caso y Bernal 2003; Marcus 2008; Sellen 2007, 2011; Urcid 2009) (Figura 2). Para algunos autores es mejor llamarlo Pitao Cociyo, el «gran espíritu del rayo», quien tiene el poder de contener o liberar el agua con ayuda de su arma, la serpiente de fuego, símbolo del relámpago que alumbra, penetra y rompe las nubes (Marcus 1983c: 346, 2008: 129; Marcus y Flannery 1994: 58). Las representaciones de Cociyo en vasijas efigie son las más abundantes dentro del sitio y en los Valles Centrales (desde Danibaan a Xoo), convirtiéndolas en el prototipo de la cultura zapoteca del Clásico y del apogeo de Monte Albán (Caso y Bernal 2003: 160; Marcus 1983b: 144, 2008: 132; Sellen 2007: 31, 159, 313).

\section{Evidencias previas para el control de agua}

Previo al surgimiento de Monte Albán, las poblaciones se asentaron en la base del valle, cerca de fuentes de agua. En los Valles Centrales la agricultura es posible en

\footnotetext{
Recientemente algunos autores han cuestionado este modelo. Winter (2011), al ofrecer una revisión de teorías sobre los orígenes de Monte Albán, rechaza el modelo de Blanton y propone uno nuevo el cual aún carece de evidencia contundente que lo respalde. En éste se plantea que el sitio fue resultado, probablemente, de un movimiento milenario que replicó el trazo arquitectónico de sitios mixe-zoques y el cual representó un nuevo ordenamiento social donde los líderes de la sociedad vivían en ambos extremos de la cima del cerro desde donde simbólicamente controlaban a la población a través de un mercado y ceremonias públicas religiosas. Por otra parte, Joyce (2004, 2010) pone en duda el militarismo en cual Blanton enfatiza en la creación del estado. Para él, Monte Albán fue un centro político y religioso resultado de una nueva identidad corporativa sustentada en principios religiosos. Como veremos más adelante en apoyo a la idea de Joyce (2004), este artículo argumenta a favor de la fuerza religiosa y ritual de Monte Albán. Más aún, es necesario reevaluar la evidencia arqueológica que tradicionalmente se ha empleado a favor del carácter bélico del sitio: el asentamiento en la cima de un cerro similar a una «fortaleza natural», murallas «defensivas» en Monte Albán y otros sitios dentro y fuera de los Valles Centrales (e.g. Teotitlán del Valle, Quiotepec, La Coyotera, Miahuatlán, Tututepec y Ejutla), rasgos estilísticos «típicos» en el acervo cerámico y arquitectónico e interpretaciones iconográficas de monumentos grabados que apuntan a la captura de enemigos, sacrificios humanos y la dominación de pueblos (siendo los «Danzantes» del Edificio L y las «Lápidas de Conquista» del Edificio J los ejemplos más comunes) (Blanton et al 1999: 62; Feinman y Nicholas 1990; Flannery y Marcus 1983: 83; Joyce 2010; Marcus 1983a, 2008; Spencer 2003; Winter 1992). Recientemente han surgido nuevas lecturas y propuestas que, si bien no se alejan del todo de la idea militarista, sí lo hacen de cierta carga de violencia. Por ejemplo, los Danzantes pudieron ser un retrato de una jerarquía de una orden guerrera-sacerdotal, grabados en el acto de autosangrado genital e invocación de ancestros (Urcid 1998, 2011a) y las lápidas de Conquista posiblemente plasmaron el viaje al inframundo de víctimas de sacrificio (Joyce 2010: 137) o constituyen la narrativa de personajes locales y pueblos aliados con Monte Albán (Urcid 2011b).
} 


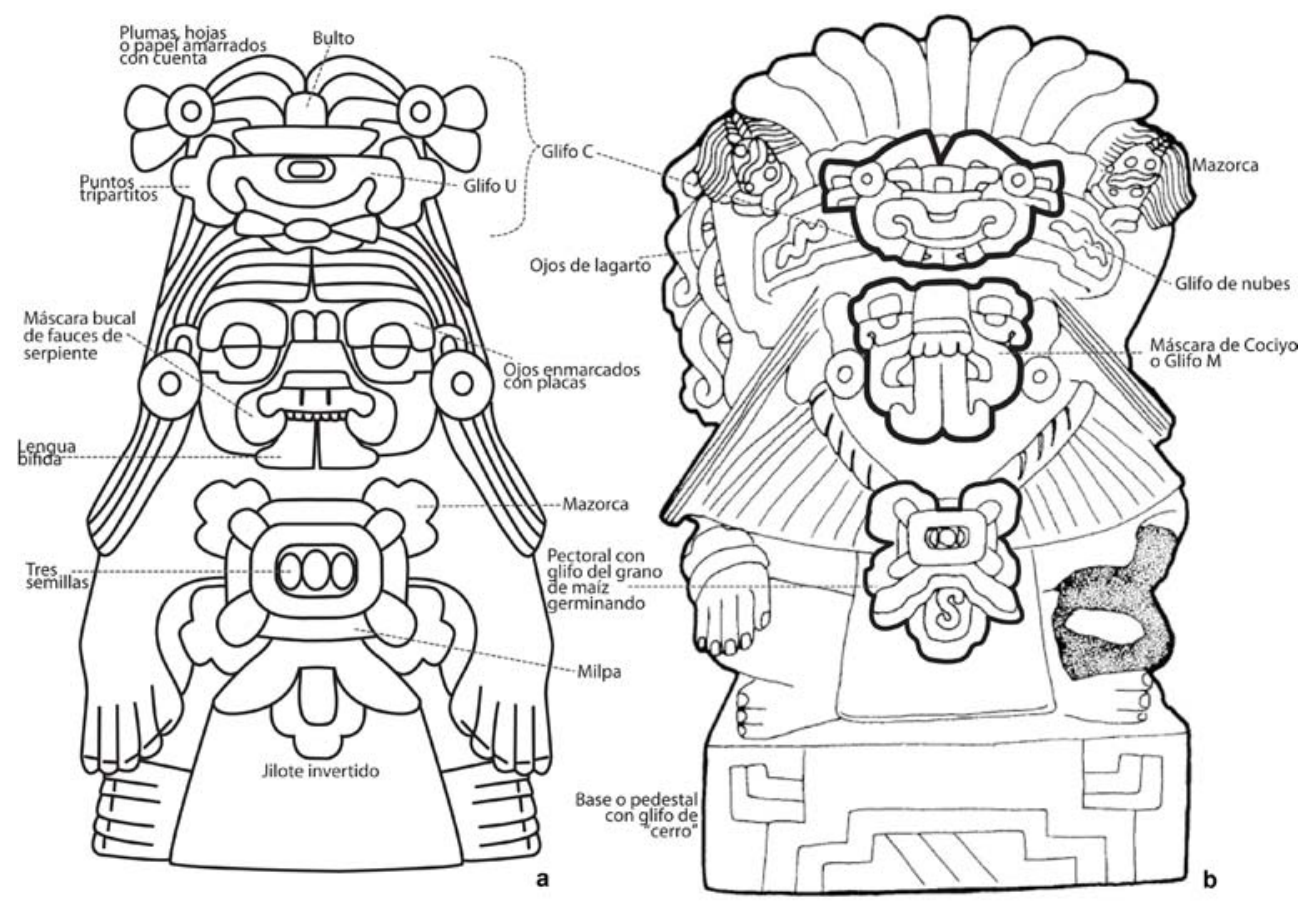

Figura 2. Vasijas efigie con máscara y atributos de Cocijo, de fase Xoo (iconografía en Sellen 2007 y Urcid 2009): a) Ejemplo sencillo (dibujo basado en Paddock 1966, fig. 117);

b) Ejemplo sobre base o pedestal con diseño piramidal que simboliza «cerro»

(dibujo cortesía de Sellen 2005, SMI 214992).

zonas donde hay acceso al gran acuífero del subsuelo (algunos años atrás, en ciertas zonas, en época de lluvias, a sólo $1 \mathrm{~m}$ de profundidad), o donde hay arroyos o ríos a pie de monte y aluvión, como en el Valle de Etla, y en el Valle Grande donde la precipitación es suficiente (siendo Tlacolula la zona más seca de los tres valles) (Kirkby 1973; Lees 1973). En el Valle de Etla, se practica el cultivo de temporal desde tiempos del Arcaico (antes del 6700 a.C.) (Flannery 1983: 324). Al deshierbar con cuidado, sembrar las semillas sin mucha profundidad y no remover tanto la tierra, se minimiza la evaporación y se conserva mejor el agua en el suelo. Este tipo de agricultura provee una cosecha al año como máximo (Flannery 1983: 324) ${ }^{6}$.

\footnotetext{
6 La cantidad de agua en los Valles Centrales no es significativamente abundante, siendo la lluvia, los arroyos y el acuífero del subsuelo las únicas fuentes del vital líquido (Kirkby 1973). La cantidad de lluvia anual es relativamente insuficiente $(500-700 \mathrm{~mm})$ y no compensa el índice de pérdida por evaporación y transpiración. Como máximo, sin irrigación, se sostiene una cosecha al año con alto riesgo de años secos, especialmente en el Valle de Tlacolula siendo mayor la precipitación en el Valle Grande y la mayor disposición de fuentes de agua en el Valle de Etla. De ahí que las poblaciones han adoptado desde tiempos remotos diversas técnicas para conservar el agua en el suelo (Kirkby 1973). Entre ellas están las terrazas en aluvión y pie de monte, muros transversales en el curso de arroyos y escurrimientos, canales para desviar el agua de ríos, arroyos y tributarios, presas que elevan el nivel de ríos y los desbordan, cultivo en tierras de humedad (de alto nivel freático), riego a brazo (pozos en los terrenos que extraen agua del acuífero), e irrigación por canales.
} 
El aprovechamiento de agua de lluvia en manantiales, arroyos y escurrimientos con el uso de pequeñas presas o canales, fue una práctica común desde tiempos tempranos en Mesoamérica (Rojas Rabiela 2009: 13). En tiempos del Formativo Medio (1400-1150 a.C.), aldeas en San José Mogote, Abasolo, Tierras Largas, Mitla y San Lorenzo Etla se establecieron junto a humedales, excavaron pozos para «alumbrar agua» y construyeron canales y depósitos para transportar agua de arroyos y manantiales permitiendo así una agricultura intensiva no sólo a nivel de aluvión pero también en pie de monte (Flannery 1983: 324-326; Kirkby 1973; Marcus 2006: 234; Marcus y Flannery 1996: 147; Neely 1967) ${ }^{7}$. Destaca en Oaxaca para este periodo del Formativo la escasa evidencia de canales para irrigar campos de cultivo (Doolittle 1990: 40).

Desde la fundación de Monte Albán se observa el incremento de canales de irrigación a lo largo de arroyos tributarios del río Atoyac, para algunos, debido a la mayor demanda de alimento para abastecer a la ciudad (Blanton et al. 1999: 116; Marcus y Flannery 1996: 146). El crecimiento de población y de desarrollo tecnológico fue de la mano con cambios en la organización social y la mano de obra y mayor especialización política en diferentes niveles de la jerarquía, volviéndose las comunidades pequeñas, responsables del manejo directo del control del agua, dependientes de los niveles altos de autoridad estatal (Lees 1973: 94, 133). Durante estos periodos, para las aldeas de los Valles Centrales, el agua de lluvia fue un recurso natural y de aprovechamiento, en estrecho vínculo con el ritual hacia Pitao Cociyo, el espíritu del rayo proveedor de agua (Marcus 2006: 229, 236) ${ }^{8}$.

En Monte Albán el estudio sobre el aprovechamiento de agua de lluvia y arroyos no ha sido extenso y las pocas investigaciones al respecto han pasado un tanto desapercibidas. Desde las primeras excavaciones en el sitio, se había notado la existencia de canales de desagüe en la plaza principal y plataformas Norte y Sur, algunos uniendo distintos complejos arquitectónicos y patios. Caso (2002: 42-45) le llamó «subterráneos» a una especie de túneles (cuatro en total) que encontró y excavó debajo de la Plataforma Norte, al oriente del montículo Q, y en los montículos oriente y poniente de la Tumba 7 . Uno de ellos con $98 \mathrm{~m}$ de longitud, $0,40 \mathrm{~m}$ de altura $\mathrm{y}$, donde desembocan desagües, tenía un entierro con un individuo en asociación a un sahumador, cuentas y adornos de jade y concha. Dada la dimensión de estos subte-

\footnotetext{
7 En Abasolo, Tlacolula, y Mitla se han hallado pozos fechados en el Formativo Medio (fase San José 1150-850 a.C.) donde el nivel freático generalmente se encuentra a $3 \mathrm{~m}$. y los cuales probablemente se usaron para el «riego a brazo» o «a cántaro» (tiquilla nicaya), con lo cual se podrían obtener hasta 3 cosechas al año (Drennan y Flannery 1983: 67; Flannery 1983: 325). Hasta hace unas décadas, en estas y otras poblaciones de los valles centrales, todavía se empleaba estas técnicas de riego (Flannery 1983: 325; Kirkby 1973; Marcus y Flannery 1996).

8 Un caso extraordinario del uso y aprovechamiento de manantiales está en Hierve el Agua (San Antonio Albarradas, Tlacolula). Ahí, el agua se distribuye por $500 \mathrm{~m}^{2}$ de un área de terrazas artificiales, por las cuales corren canales de cientos de metros, sobre los cuales hay depósitos o pocitos cada $3 \mathrm{~m}$ aproximadamente y algunos registros (rectangulares) principalmente asociados a los estanques de más de $5 \mathrm{~m}$ de largo (en la parte de arriba del cerro) (Doolittle 1989; Hewitt et al. 1987; Kirkby 1973: 119; Neely 1967). El alto nivel de minerales en el agua ha hecho que se preserven en roca de travertino estos sistemas hidráulicos que datan desde el siglo V a.C. hasta época de la llegada de los españoles (Neely 1967, mayormente del 500 al 1250 según Hewitt et al. 1987: 807). Se piensa que las terrazas, canales, pocitos y registros fueron usados para controlar y detener el flujo del manantial que corre cuesta abajo y así aprovechar el agua para el riego de cultivos (Doolittle 1989; Kirkby 1973; Neely 1967). Otros piensan que el sistema es evidencia de tecnología para la producción de sal (Hewitt et al. 1987) o, la materialización del concepto mesoamericano de la montaña llena de agua de la cual emana agua y sustentos para la población, es decir, el «Monte Sagrado» o «Montaña de Mantenimientos» (Flores Granados 2016).
} 


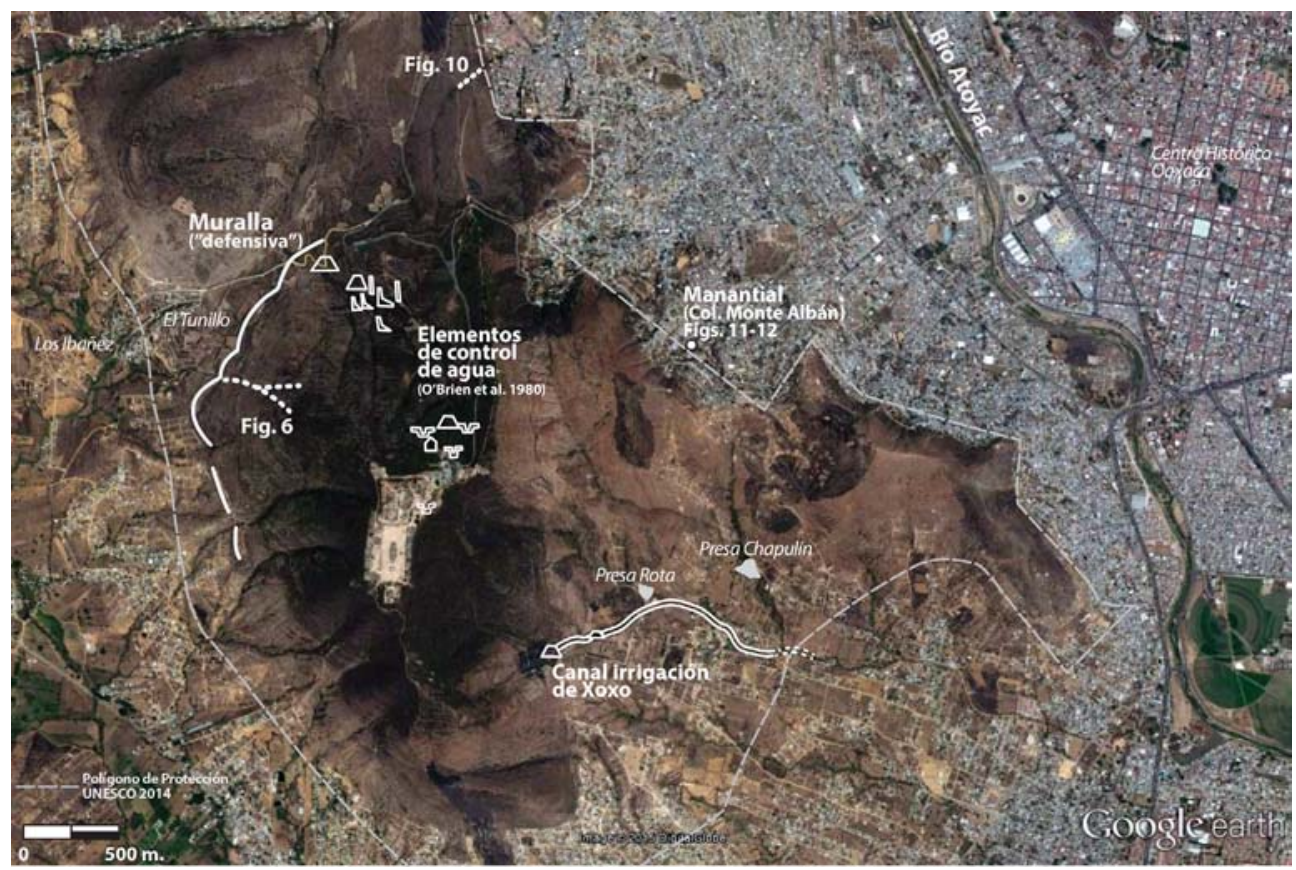

Figura 3. Evidencia arqueológica en el manejo de agua en Monte Albán (mapa elaborado a partir de O'Brien et al. 1980, datos de este artículo y comunicación personal del Arqlgo. Dante García).

rráneos hallados con las extremidades cerradas, a veces con toscas vasijas, se les ha sugerido como depósitos de agua para estos templos (Caso 2002: 45).

Posteriores estudios en las Plataformas Norte y Sur revelaron sistemas en declives y canales que captaban el agua de lluvia que, a la vez, permitían el desagüe de templos y patios y la conducían a campos de cultivo para irrigarlos, creando una especie de reciclaje de agua (Sansores 1992).

En la década de los 70, James Neely y Michael O'Brien registraron una serie de drenajes, muros y canales que conectaban verticalmente entre terrazas fuera y al norte y noreste de la plaza principal y área monumental (O'Brien et al. 1980: $345)$ (Figura 3). Sus hallazgos incluyen pequeños drenajes $(8-10 \mathrm{~cm})$ en complejos residenciales, en patios abiertos y cuartos, y canales de paso más grandes (25-40 $\mathrm{cm}$ ), con tapas de piedra que los cubren, generalmente a $1 \mathrm{~m}$ bajo superficie y algunos tan largos como de $170 \mathrm{~m}$ lineales (éste desde el Montículo X hacia el norte), con elementos escalonados o pozos para controlar la caída del agua. En esta área inmediata a la Plataforma Norte, registraron un estanque de grandes dimensiones (15 m de ancho y $18 \mathrm{~m}$ de largo), quizás en su momento conectado a los drenajes antes mencionados, con compartimientos de distintas elevaciones en el interior para retener sedimentos y una presa adyacente que permitía la salida de agua limpia en la parte superior del estanque (O’Brien et al. 1980: 347). En el extremo poniente del estanque hay una presa ( $3 \mathrm{~m}$ de ancho y $20 \mathrm{~m}$ de largo) la cual bloquea una barranca y crea un depósito de agua de $1.500 \mathrm{~m}^{2}$ de superficie (O'Brien et al. 1980: 349). Este sistema es único pues no tiene una fuente natural de origen, sino que es un diseño 
que recicla el agua (de lluvia) (Lees 1973). Más abajo en la pendiente, al poniente, existen muros que detienen el agua y evitan la erosión del terreno, a la vez que canalizan el agua dentro de barrancas o escurrimientos, uno de ellos con $50 \mathrm{~m}$ de longitud y otro siendo la llamada «muralla defensiva» (bautizada así por Blanton 1978: 52) cuya función adicional (sin rechazar tampoco el carácter de fortificación de la misma) fue la de reservar agua en un gran tanque con capacidad de $67.500 \mathrm{~m}^{3}$ aproximadamente (Neely 1972: 13; Neely y O'Brien 1973; O'Brien et al. 1980: 347)9 . Muy cerca de la llamada muralla hay otra presa construida en conjunción con afloramientos naturales de piedra, los cuales forman una caída de $4 \mathrm{~m}$ creando un gran depósito en este escurrimiento (O'Brien et al. 1980: 350). Ligeramente más arriba, hay también una serie de muros (de 6 a $15 \mathrm{~m}$ de largo y $1 \mathrm{~m}$ de altura) construidos sobre barrancas que funcionan como pequeñas presas, captando el agua que escurre, y probablemente para canalizarla hacia terrazas agrícolas adyacentes $(\mathrm{O}$ 'Brien et al. 1980: 350). Ahí, hay un muro de $45 \mathrm{~m}$ de longitud que forma un dique sobre otro escurrimiento provocando que el agua se acumule en una terraza (núm. 643) siendo un terreno ideal para el cultivo (O'Brien et al. 1980: 350).

En cuanto a sistemas de irrigación, se han hallado tres al sur del cerro, en Monte Albán Chico. Uno de ellos, construido en una barranca natural del cerro, tiene una presa, un depósito de agua y un canal (Mason et al. 1977; Neely 1972; Neely y O’Brien 1973; O’Brien et al. 1982) (ver Figura 3). Este sistema es único en su género, con un área residencial adyacente, considerado el más temprano hasta ahora reportado en el continente (600-400 a.C., aumentando de tamaño del 550-150 a.C.) (Martínez Ruíz y Murillo Licea 2009: 212; Mason et al. 1977). La presa es de tipo bóveda, con forma en «V», de aproximadamente $10 \mathrm{~m}$ de altura en el centro y longitud de $80 \mathrm{~m}$, hecha de piedras calizas y relleno de rocas (O'Brien et al. 1980). La evidencia parece indicar que tenía una compuerta al centro (Doolittle 1990: 32). El canal en el extremo sur de la presa, tiene dos km de largo, es escalonado (canal inferior de $80 \mathrm{~cm}$ de ancho por $25 \mathrm{~cm}$ de profundidad, y canal superior de $30 \mathrm{~cm}$ de ancho por $12 \mathrm{~cm}$ de profundidad) sigue el contorno de la montaña y baja por el pie de monte hasta el fondo del valle, desembocando en un arroyo, pasando por terrazas agrícolas a ambos lados (O'Brien et al. 1982). En algunas partes, el canal principal está biselado directamente de la roca madre (Mason et al. 1977: 567). No se encontraron canales o ramales secundarios por lo que se piensa que el sistema irrigaba por inundación los terrenos anexos (Doolittle 1990: 34). El área cultivada es de 50 ha con un área residencial de 2,5 ha lo cual probablemente alcanzó para alimentar a un máximo de 250 personas, con dos o tres cosechas al año (Mason et al. 1977; O’Brien et al. 1980), siendo no obstante insuficiente para mantener la población del sitio en aquel momento (5.000 personas, aprox., Blanton et al. 1999: 91).

\section{Nuevos hallazgos}

En el verano del 2014, se realizó un breve recorrido de superficie (cinco días de trabajo) en las laderas oriente y norte de Monte Albán en donde se pudo se pudo ve-

\footnotetext{
Para Blanton (1978: 52) esta muralla que en algunos puntos alcanza los 9 metros, además de cumplir la función de defensa de la ciudad y servir para la reserva de agua, fue quizá también una puerta que regulaba el tráfico de salida y entrada de personas al sitio, en un punto donde coinciden antiguos caminos.
} 


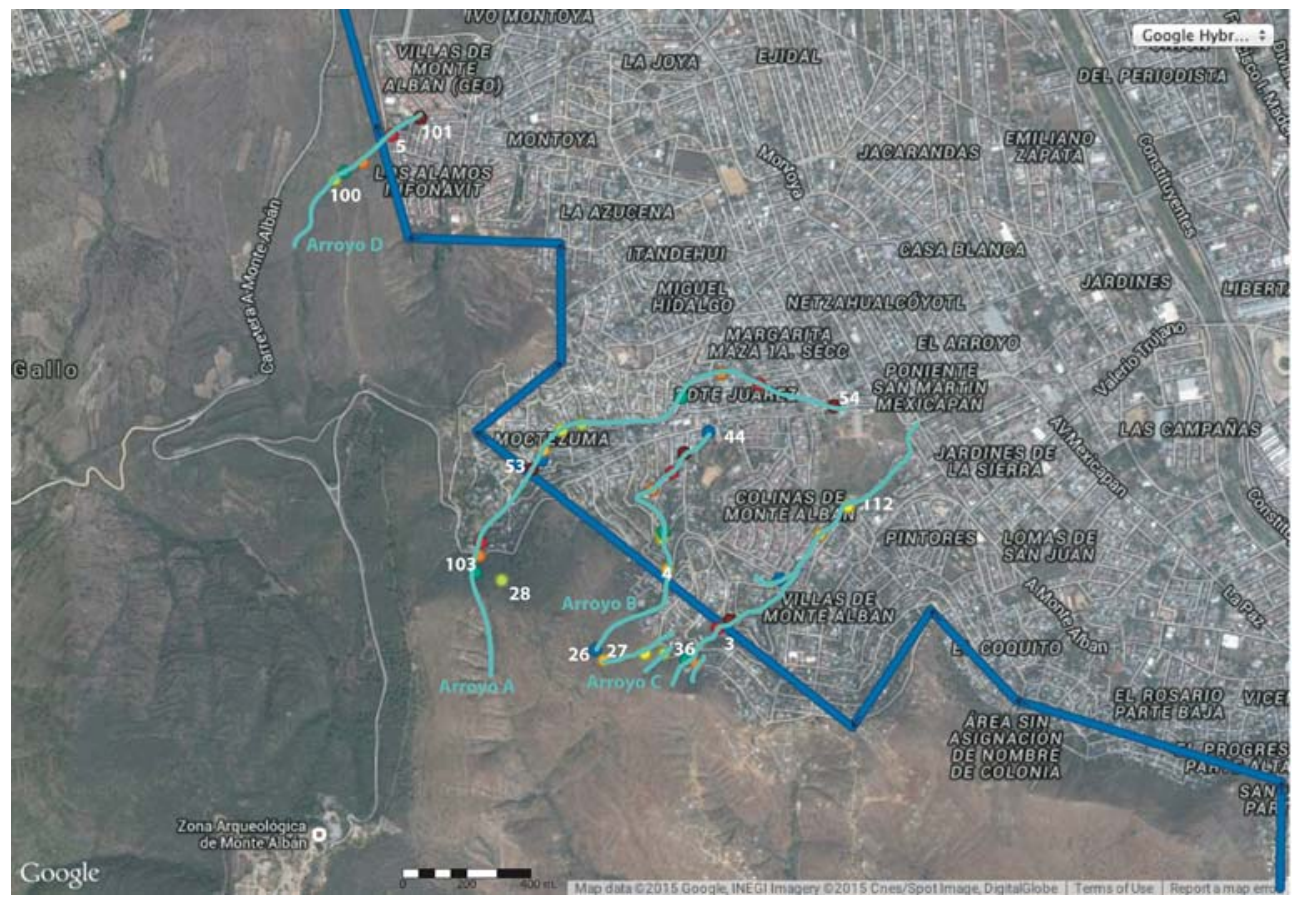

Figura 4. Escurrimientos y arroyos verificados en campo que tienen su origen en la cima de Monte Albán y pasan por colonias de Mexicapam y Montoya.

rificar que en el cerro corre y nace de él agua, así como técnicas que se usaron para controlar el líquido que escurre (Rojas 2015).

En primer lugar, se identificaron en campo cuatro arroyos (A, B, C y D) que tienen su origen dentro del polígono de protección de la zona de Monte Albán y los cuales siguen su curso por las colonias de Mexicapam y Montoya (Figura 4). Efectivamente se comprobó que tienen origen en la cima del cerro en forma de diversos escurrimientos los cuales se unen pendiente abajo en arroyos los cuales desafortunadamente se encuentran obstruidos por calles, casas e incluso se encuentran ya entubados en desagües de concreto.

Uno de los arroyos en particular merece una importante mención, el denominado Arroyo C. Éste tiene su origen en una serie de escurrimientos y arroyos en el cerro de El Mogollito, los cuales cruzan debajo de la carretera a Monte Albán (justo al lado de la Plaza Comunitaria SEP/INEA). Debajo de la carretera el agua sale de la tierra donde además hay construcciones hechas de piedra y cemento para el control y canalización del agua: un puente, muros y canales (Figura 5). Un poco más abajo, los vecinos de la Colonia Monte Albán, Mexicapam, construyeron una jaula en cuyo interior hay una manguera por donde sale agua de manera constante. Enfrente, hay una tubería que conecta con un pozo y pocos metros más abajo hay una serie de lavaderos. Ahí, el agua sigue su curso, bajando por la calle ya cementada de Huijazoo, hasta llegar a la Calle de Monte Albán, donde se une con otros arroyos hasta llegar al río Atoyac. En estos puntos, la cantidad de agua es ya reducida y está contaminada, debido a constantes obstáculos entre calles, casas y basura. 

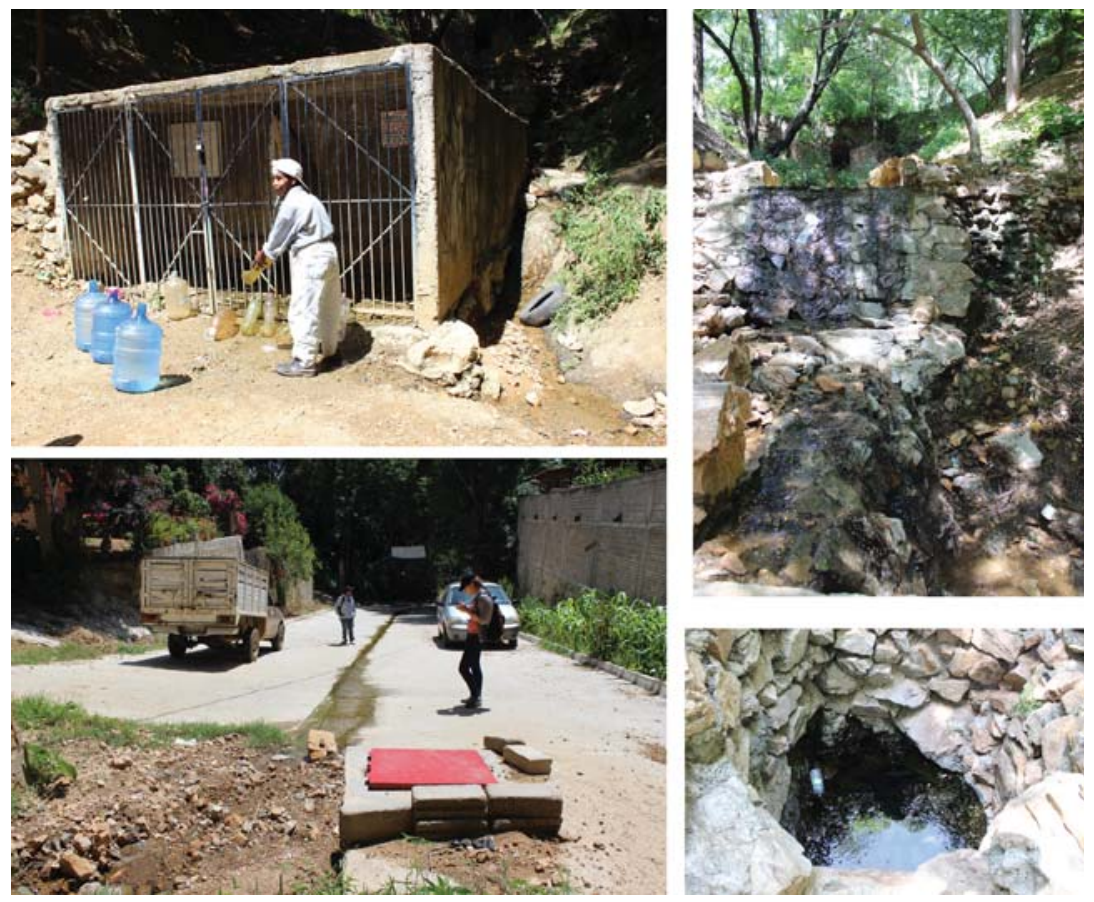

Figura 5. Nacimiento y curso del manantial de la Colonia Monte Albán, Mexicapam.
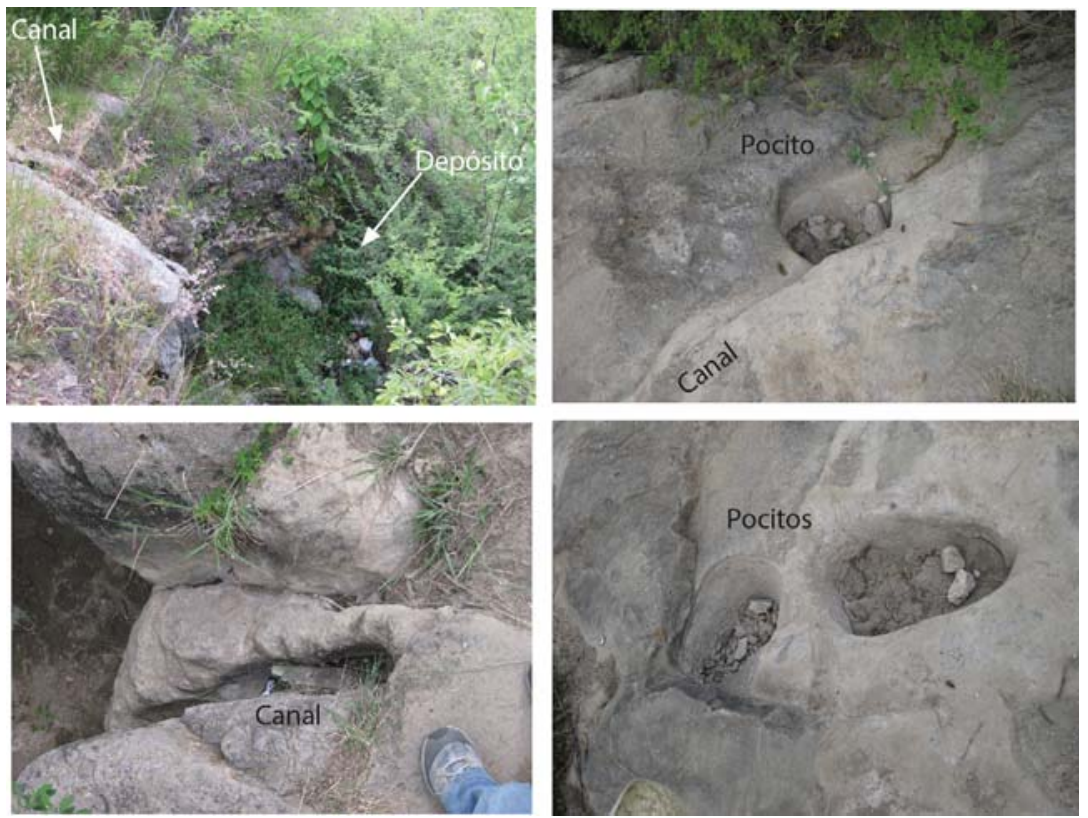

Figura 6. Canales y «pocitos» en arroyo que baja y pasa por la agencia de Montoya. 


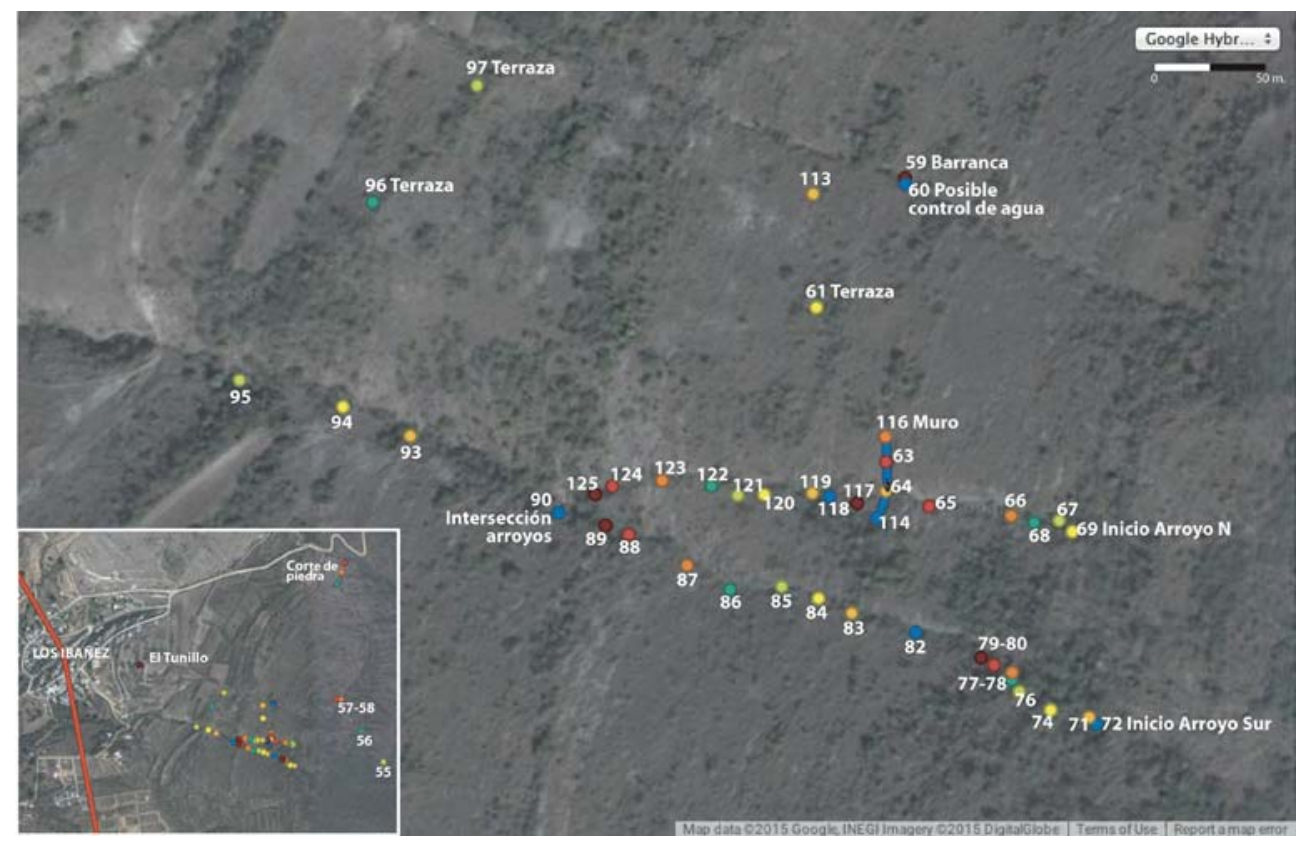

Figura 7. Ubicación de los Arroyos Norte y Sur (cada uno de los puntos corresponde a evidencia arqueológica para el control de agua).

En otro arroyo que baja desde el cerro y pasa por la calle Yaa, colonia Álamos de Infonavit, Montoya, hay canales y oquedades excavados en la roca madre, los cuales probablemente funcionaron para controlar y contener agua (Figura 6). Algunos de los pozos, de aproximadamente $30 \mathrm{~cm}$ de diámetro, poseen similitud con los «pocitos» de Hierve el Agua (ver Doolittle 1989; Kirkby 1973). Cabe señalar el estado de erosión en la superficie, similar a las huellas que deja el paso del agua.

Con el fin de conocer mejor sistemas de control de agua en arroyos y escurrimientos, se realizó un recorrido por el lado noroeste de Monte Albán, cercano a áreas donde Neely y O'Brien habían ya registrado múltiples elementos de control de agua, en concreto, al oeste de la Plaza Principal, pendiente arriba de los montículos de El Tunillo (Figura 7). Ahí, dentro de dos escurrimientos (los cuales llamamos Arroyo Norte y Arroyo Sur) que convergían en uno, en dirección oriente a poniente se halló evidencia muy similar a las ya antes descritas por estos autores, ubicada al Norte de la Plaza Principal y al canal de irrigación de Xoxo. A lo largo de $400 \mathrm{~m}$ aproximadamente, siguiendo el curso de estos arroyos (no perennes) hay alrededor de 34 elementos de manejo del agua, espaciados entre 7 y $40 \mathrm{~m}$ de distancia, funcionando como contención, reserva, drenaje y canalización de agua hacia terrenos contiguos, algunos en terrazas a lo largo de la pendiente.

Existen excavaciones en el curso del escurrimiento que crean pozos (aprox. 14) al interior, algunos haciendo uso de la posición natural de grandes piedras en el curso del arroyo funcionando como muros que sostienen el depósito (Figuras 8-9). Algunos casos tienen muros construidos con piedras careadas, lajas, lodo y gravillas en 
Figura 8. Pozos, muros y canales dentro de los Arroyos Norte y Sur.
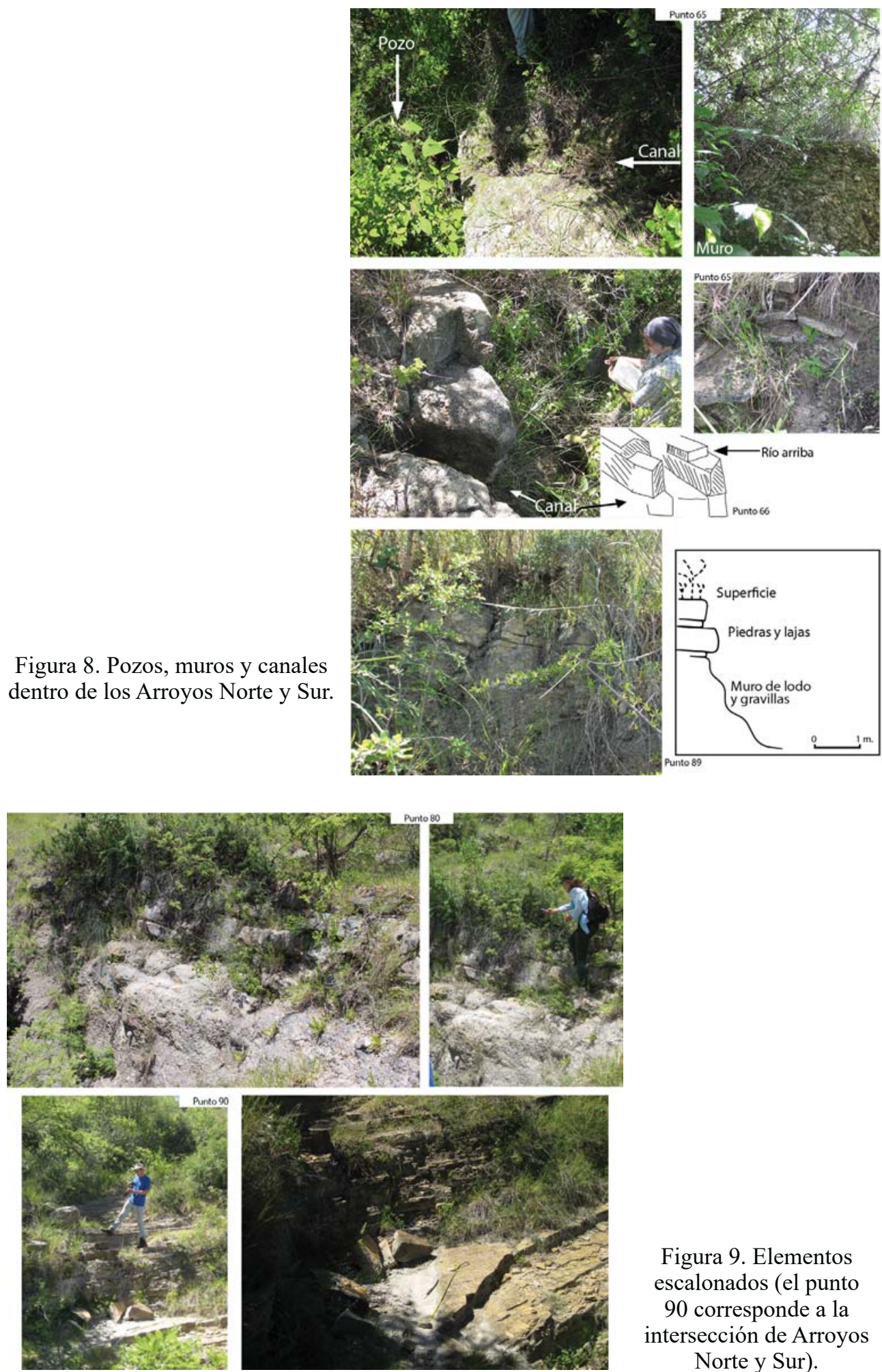

Figura 9. Elementos escalonados (el punto 90 corresponde a la intersección de Arroyos Norte y Sur). 


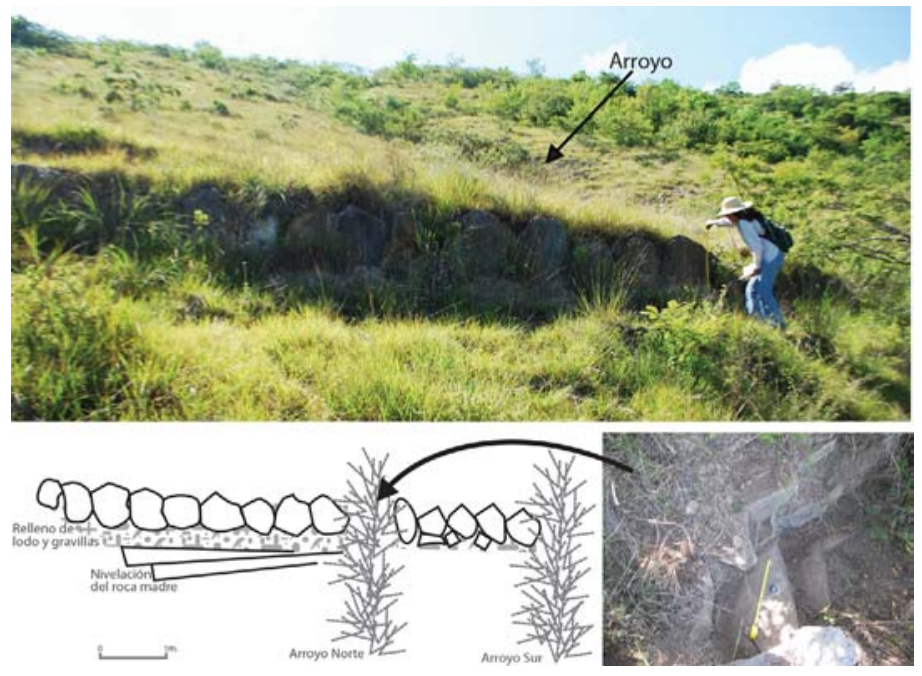

Figura 10. Muro y pozo escalonado en forma de «V», intersectando Arroyo Sur (punto 64).

el lado río arriba del escurrimiento. Estos muros van de 1 a $2 \mathrm{~m}$ de altura, aproximadamente. Algunos de estos muros poseen canales en el borde contra-corriente, como para dirigir el agua con mayor precisión. También se registraron una serie de elementos escalonados (aprox. 17), algunos seccionados desde la roca madre o construidos con piedras y lajas, formando una figura en « $\mathrm{V} »$ dentro y hacia el lado río arriba del escurrimiento (ver Figura 9). Algunos de ellos crean una cavidad al interior, como un embalse, el cual también contiene y dispersa el agua hacia las terrazas inmediatas, probablemente para uso agrícola. Esta tecnología es la misma que fue descrita para el canal de irrigación de Xoxocotlán.

Destaca entre este grupo un muro de más de $15 \mathrm{~m}$ de largo y $0,6 \mathrm{~m}$ de alto, el cual corre transversalmente y atraviesa por uno de los arroyos, con dirección norte (con piedras de 40 a $50 \mathrm{~cm}$ y otras de 10 a $20 \mathrm{~cm}$ usadas como juntas entre las grandes) (Figura 10). El muro está sobre el florecimiento de la roca madre (característico en esta zona por ser laminar) y fue biselado para nivelar el terreno. El muro es similar a la muralla «defensiva» y los elementos ya antes descritos por O'Brien y colegas (1980: fig. 2a). En el punto donde el muro intersecta el arroyo hay un elemento de piedras trabajadas con un arreglo de tipo escalonado en forma de «V», el cual crea una especie de pozo de aproximadamente $1 \mathrm{~m}$ de profundidad desde la superficie del terreno. Como el muro, la junta entre piedras tenía lodo y pequeñas lajas. En conjunto, el pozo y el muro crean una presa la cual bloquea el agua del escurrimiento, la contienen al interior y a la vez la extienden a terrenos aledaños, probablemente para el cultivo.

Este muro es similar a técnicas contemporáneas de cultivo donde en arroyos no perennes y escurrimientos de los cerros se construyen muros transversales, construidos con piedras, lodo y ramas, menos de $1 \mathrm{~m}$, en longitud de 3 a $30 \mathrm{~m}$, comúnmente de $10 \mathrm{~m}$, a nivel de pie de monte, o también en la base del valle (Kirkby 1973: 38). Estas barreras proveen de áreas planas que además detienen y conservan agua, siendo reservas de humedad. Las terrazas a su alrededor se impregnan de esta humedad, las cuales podrían no ser usadas en época de lluvias por riesgo de mucha humedad, 
Figura 11. Depósito que recolecta el agua de arroyos, seccionado en roca madre con canales.
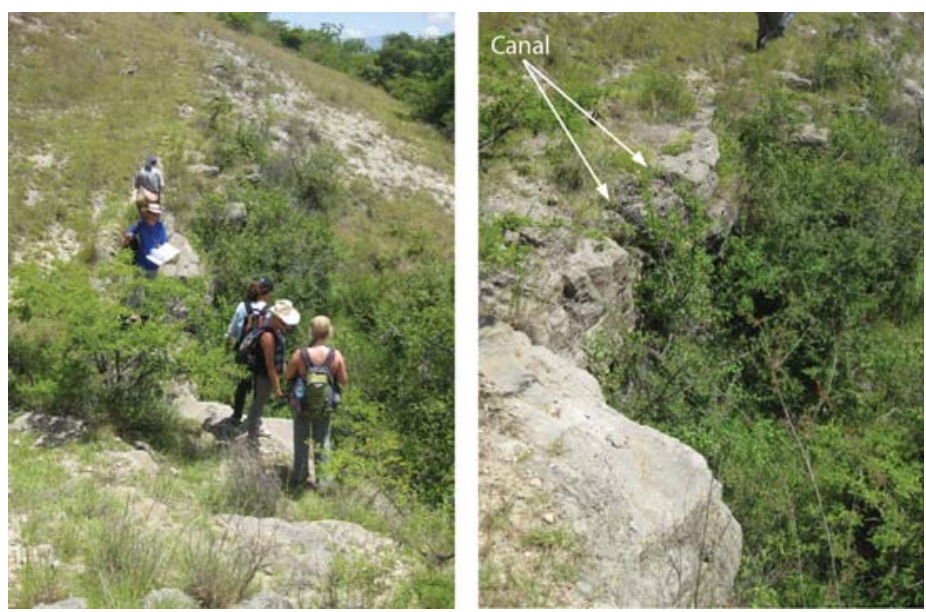

pero bien sí durante el invierno, siendo apropiadas para el cultivo de frijol (Kirkby 1973: 38).

Otro elemento a destacar durante el recorrido fue un gran depósito trazado debajo de los Arroyos Norte y Sur, el cual parece estar formado por el corte natural de la roca madre del cerro, también de forma escalonada, con una profundidad mayor a los $2 \mathrm{~m}$ de altura (similar al elemento de O'Brien et al. 1980: fig. 2a5) (Figura 11). Éste parece ser una gran reserva de agua donde termina de recolectarse el agua de ambos arroyos previamente controlados, casi en la base del cerro, a aproximadamente $50 \mathrm{~m}$ de la muralla («defensiva»).

A lo largo del recorrido por estos arroyos se observó relativamente poco material cerámico. No obstante se identificaron tiestos de cerámica gris, de superficie erosionada, bordes de ollas pequeñas, de grosor delgado, cuellos curvo-divergente, bordes evertidos, similares al tipo G3, diagnóstica de Época I y II (500 a.C. a 200 d.C., o fases Danibaan y Niza) (Caso et al. 1967: 24-25, 219, figs. 127, 185, 186c).

\section{Monte Albán, cerro donde corre agua}

El reciente recorrido de superficie, así como previamente lo había hecho Neely, O'Brien y sus equipos, confirman la presencia de agua corriente en Monte Albán la cual sus antiguos habitantes aprovechaban y controlaban. En escurrimientos y arroyos perennes excavaron y construyeron pozos, algunos tipo embalses, diques y canales que dirigían y almacenaban agua, deteniendo su flujo cuesta abajo. A lo largo de estas pendientes crearon terrazas y muros que extendían el agua, muy probablemente para fines de cultivo. No es casualidad que las zonas donde se ha encontrado esta tecnología, la zona norte, noreste y noroeste, coincide con una gran cantidad de terrazas artificiales. Muy probablemente esta agua sirvió para irrigar terrenos de cultivo.

Blanton (1978) afirmó que las terrazas de Monte Albán no fueron aptas para la agricultura y sólo fueron usadas para habitar en ellas. La nueva evidencia aquí presentada no necesariamente contradice esta opinión, ya que las terrazas bien pudieron ser tanto agrícolas como habitacionales. Pueblos mesoamericanos, del pasado y el presente, cultivan junto donde ubican sus hogares. El espacio habitacional y domés- 
tico incluye áreas de cultivo. El mismo equipo que acompañó a Blanton notó que las pendientes estaban cubiertas con milpas que dependían sólo del agua de temporal de mayo a octubre, sin la necesidad de un sistema de irrigación adicional (Neely y O'Brien 1973: 17). Hoy en día, varias familias que han reocupado el cerro, muchos de ellos originarios de comunidades agrícolas e indígenas de Oaxaca, cultivan maíz en sus terrenos, junto a sus casas.

El manantial registrado en este recorrido es un dato con mucha relevancia, ya que representa una evidencia que refuta la carencia de fuentes naturales en el cerro $\mathrm{y}$, aunque no está directo en la cima, se encuentra a $1 \mathrm{~km}$ de distancia de la Plaza Principal y en medio, con escasos $500 \mathrm{~m}$ de distancia, de terrazas habitacionales registradas por Blanton (1978) y de dos sitios previamente registrados en el recorrido de Stephen Kowalewski (1976). Dichos sitios son el C-L1-151 y C-L1-152, los cuales corresponden a época I Tardía o Danibaan (300-100 a.C.). Del primero sólo se tiene registrada la presencia de cerámica pero del segundo hay tres montículos de relativo tamaño pequeño (20x20x1 m aprox.) y tiestos que abarcan también épocas Pitao (200-600 d.C.), Liobaa (800-1200 d.C.) y Chila (1200-1521). Es probable que el manantial fuera fuente de agua para esta población de máximo 100 personas.

Los datos de pocitos y canales en el Arroyo D de Montoya están asociados a los sitios C-II-22, C-IIIA-33 y C-IIIB-214, ubicados a escasos $100 \mathrm{~m}$ de dichos sitios y pertenecientes a las épocas Niza (200 a.C.-200 d.C.), Pitao (200-600 d.C.) y Xoo (600-800 d.C.). Desafortunadamente, igual para el caso de los sitios antes mencionados, los restos arqueológicos han sido arrasados por el avance urbano y actividad agrícola.

La evidencia aquí presentada es sólo una pequeña muestra de la tecnología de control de agua en Monte Albán, la cual es posible que se encuentre en numerosos afluentes del sinuoso cerro aún no explorados. Representa tan solo un acercamiento hacia la posibilidad de realizar un proyecto mayor usando un sistema de información geográfica (GIS) el cual permita analizar los afluentes y sistemas de control de agua en Monte Albán y conocer su capacidad de retención de agua limpia para uso humano (watershed analysis). En este análisis es importante considerar que las fuentes de agua recorriendo el cerro fueron más numerosas y abundantes en tiempos prehispánicos. En los últimos 50 años, las áreas verdes y de cultivo alrededor del cerro se redujeron un 70 por ciento y las zonas urbanas casi se quintuplicaron (Rojas y Beccan en prensa). Esta intensa deforestación ha reducido en demasía las reservas acuíferas que emanan del cerro lo cual inhibe que en la actualidad veamos y comprendamos totalmente la capacidad que tuvo el cerro para proveer de agua en el pasado, para una población que dejó de ocupar el sitio hace más de mil años.

No obstante, una investigación actualizada en sistemas de control del agua en el sitio permitirá reevaluar si la imagen del «cerro sin agua», sin fuentes naturales de agua para uso humano, ni terrenos útiles para la agricultura sigue vigente. Como ya avanzaron Neely, O'Brien y Sansores, en Monte Albán se usó una sofisticada red de sistemas de drenajes, canales, muros, pozos y depósitos los cuales aprovechaban sobre todo el agua de lluvia para almacenarla y usarla en irrigación. Los resultados de este recorrido se adhieren a esta opinión, e incluso es posible sugerir, dado que estos sistemas datan de épocas muy tempranas, que Monte Albán fue pensado como un gran proyecto urbano para el cual se estudió en detalle la construcción de esta red de agua desde su fundación (Lovett 2015). 
Como apuntó Karl Wittfogel (1957), el manejo del agua implica un gran esfuerzo de organización social y movilización humana (pero es importante tener en cuenta también que las sociedades hidráulicas se organizan a nivel de la comunidad local sin la intervención del estado). Controlar el agua implica emplear energía y tecnología que aproveche la fuente de donde se obtiene, así como interrumpir y redirigir su curso, almacenarla, recolectarla, y drenarla. Monte Albán es sin duda muestra de un gran esfuerzo en la coordinación social la cual logró modificar la cima del cerro, aplanarlo y ahí construir un gran centro ceremonial con una gran plaza rodeada de templos y docenas más de edificios y cientos de terrazas, donde la tecnología para el control del agua seguramente no fue un aspecto improvisado (se tuvo que pensar detenidamente en cómo evitar que la cima se convirtiera en una enorme alberca). Resulta esta gran obra el resultado de un desarrollo tecnológico visto en los Valles Centrales desde el Formativo Temprano (circa 1200 a.C.), donde sitios controlaban y aprovechaban el agua de lluvia en el suelo y subsuelo, en arroyos permanentes y perenes, con el uso de pozos, canales y terrazas. Estas técnicas fueron producto de un profundo conocimiento del paisaje, el sistema natural de la cuenca y su manto freático, demostrado así por el diseño de formas muy sofisticadas como el uso de muros, presas, bóvedas, compuertas, depósitos y canales de irrigación, como el de Xoxo con dos km de longitud. Sin embargo, aún faltan más estudios que ayuden a comprender mejor cual fue la relación de estos sistemas tecnológicos con sus habitantes e instancias de poder y autoridad.

\section{6. Últimas reflexiones sobre el simbolismo de Monte Albán como altepetl}

Con estas ideas en mente, vale la pena investigar si Monte Albán es un caso similar al de Tikal, en el área del Petén maya, el cual también se encuentra lejos de ríos pero en donde aun así el agua en el paisaje fue un aspecto determinante para la planeación y construcción del sitio. Tikal también fue construido modificando deliberadamente un amplio espacio para captar el agua de lluvia cuyos escurrimientos alimentaban diversos depósitos (aguadas o reservorios), grandes y pequeños, a través de un sistema hidráulico que abastecía a la ciudad (Scarborough 1998). En otras palabras, Tikal sería una auténtica «montaña de agua» donde además elites y gobernantes promovían activamente una ritualidad alrededor del agua para lograr el sustento humano e ideológico que dicha magna obra de ingeniería requería.

Similar a Tikal, algunos elementos en Monte Albán parecen funcionaron como espejos de agua en la Plaza Principal; uno de ellos con asociaciones al agua y construido ex profeso para crear una superficie acuífera perenne. Enfrente del Montículo $\mathrm{H}$ se encuentra un adoratorio de cuya excavación provienen cinco cajas cuadrangulares de barro, con tapa plana, agarradera con el motivo «ojo de réptil», con pintura naranja, y decoradas con incisiones que se han interpretado como «agua» (fase II o Niza 200 a.C.-200 d.C., Caso et al. 1967: 253-255, lam. XII, fig. 233) (Figura 12). Para Robert Markens (2011: 520-523) la agarradera representa un cerro en cuya cima «brotan» plantas que son metonimia del maíz y en el que están incisos, en algunas cajas, medias lunas que simbolizan cuevas. El cuerpo de las cajas tiene en cada cara un cartucho cuadrangular con los mismos elementos vegetales antes mencionados en cada esquina. Para Markens, este motivo representa un cerro lleno de agua visto 


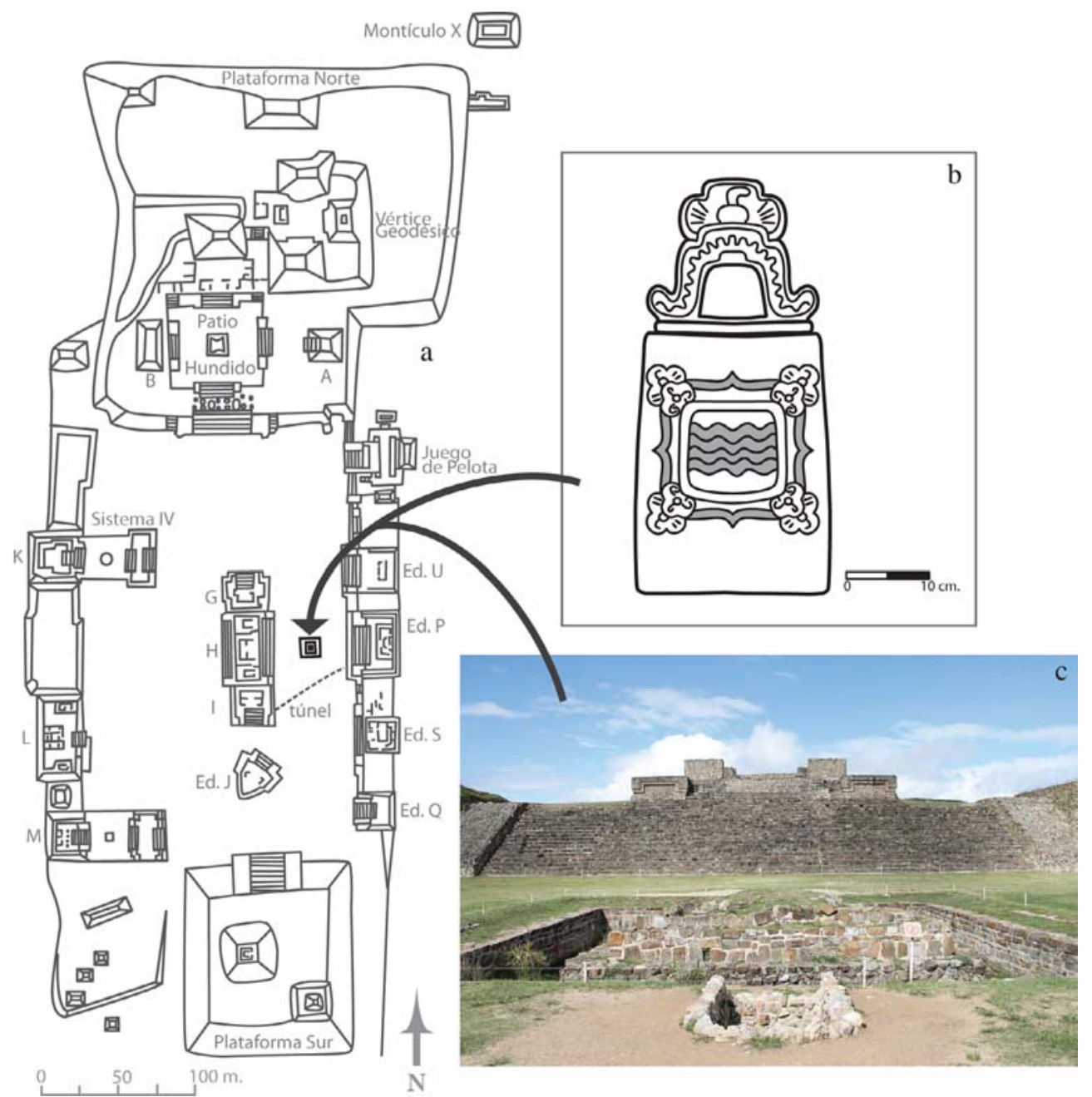

Figura 12. El adoratorio del Montículo $\mathrm{H}$ y sus asociaciones al agua: a) dibujo de sitio a partir de Marcus 2008: fig. VI.2; b) dibujo de caja de agua a partir de pieza expuesta en el Museo de las Culturas, Oaxaca; c) foto del adoratorio del Edificio H, Monte Albán (Creative Commons, consultado 2015).

en corte horizontal con plantas en cada dirección del mundo, siendo esta perspectiva una proyección común en el arte mesoamericano.

De este contexto arqueológico también proviene la majestuosa máscara de jade que representa a un murciélago (identificación recientemente cuestionada, Navarro y Arroyo-Cabrales 2013: 589) y asociada a un individuo (sexo no identificado) en un entierro múltiple (cinco individuos en total, Entierro XIV-10) (Acosta 1949). El adoratorio, compuesto por una estructura rectangular sumergida y un altar al centro, comunicado por medio de túneles (o drenajes) hacia el poniente y oriente (Edificios $\mathrm{H}$ y P), da la impresión de haber funcionado como un estanque o espejo de agua. Si el adoratorio creaba una superficie acuosa, probablemente fue escenario de rituales 
en la petición de agua, o funcionó de manera similar a la interpretación que Scarborough (1998: 152) otorga a los depósitos de agua inmediatos a los templos más importantes en Tikal, los cuales fueron concebidos como un portal («fauces») entre este y el Otro Mundo y usados en el drama ritual de las élites para reforzar su vínculo y control sobre el agua.

Otro posible depósito de agua se halla en frente del muro de los Danzantes, donde existe una depresión cubierta de depósitos de arcillas finas en donde naturalmente se acumula agua y posiblemente ocurrieron rituales para el sustento (Winter 2011: 407). Esto concuerda con la narrativa conmemorativa del muro propuesta por Javier Urcid (1998) quien señala que ahí se plasmó una gran ceremonia de auto-sacrificio genital realizada por hombres importantes, posiblemente mandatarios locales y de otras regiones, en tiempos de la fase Danibaan.

Otros datos del registro arqueológico en Monte Albán también aluden al agua. Por ejemplo, de épocas tempranas (Danibaan 600-200 a.C.) existen numerosas piezas cerámicas (cajetes, platos, ollas, efigies, miniaturas) con forma de caracoles, peces, patos y ranas (Caso et al. 1967: figs. 104, 110; Paddock 1966: figs. 9, 17, 22) de las cuales aún no hay un entendimiento claro (ya señalado así por Winter 2009: 510).

No obstante, la evidencia más contundente para el agua se encuentra en las abundantes referencias a Cociyo, dios del Rayo, señor y dueño de la lluvia. Contrario a la opinión de Blanton (1978: 80), quien sugirió que no había una sola deidad principal, Monte Albán presenta más asociaciones a Cociyo que a ninguna otra divinidad. Representado en forma de vasijas efigie y grabados en piedra, es sin duda el objeto de culto principal en la plaza, templos, casas y tumbas de Monte Albán.

La ritualidad y la visión sagrada hacia las entidades del Rayo y la Lluvia entre poblaciones zapotecas contemporáneas de los Valles Centrales, las Sierras Norte y Sur y del Istmo ofrecen datos que pueden ayudar a comprender mejor la relación entre Cociyo y sus lugares (altares) de culto, en este caso con los cerros. En pueblos de la Sierra Sur, el Rayo es un dios, dueño del agua, la lluvia, las plantas, los animales y la riqueza, que vive dentro de un cerro, al cual se puede acceder, «delicadamente», a través de cuevas, ciénagas o manantiales (González Pérez 2012). Así también, narraciones a inicios del siglo XX sobre Cociyo nos ofrecen una visión de la morada de este dios quien fue considerado la deidad principal del mundo, el benefactor del agua, pero también el verdugo.

«En la cumbre de una montaña vivía desde antes del amanecer del mundo el Viejo Rayo de fuego, Cocijoguí. Era el rey y señor de todos los rayos grandes y pequeños. Al pie de su trono deslumbrante tenía bajo su custodia cuatro inmensas ollas de barro donde guardaba encerrados, en una, a las nubes; en la otra, al agua; en la tercera, al granizo, y en la cuarta, al aire. Cada una de estas ollas, a su vez, estaba vigilada por un rayo menor en forma de «chintete» o lagartija» $(\text { Cruz 1946: } 33)^{10}$.

\footnotetext{
${ }^{10}$ Vasijas efigie con atributos del dios del Rayo, muchas de ellas ahora en colecciones de museos, se han encontrado idénticas y por cuadriplicado, sugiriendo que originalmente fueron depositadas en cuadrantes dentro de tumbas para reproducir este relato (Sellen 2002). En el montículo 7 del sitio Los Mogotes de Xoxocotlán, en la entrada de lo que fue una tumba y cerca de un horno y el extremo de una tubería de barro (probablemente de desagüe), fueron descubiertos una efigie de cerámica con rostro humano al centro flanqueada por cuatro efigies de Cociyo portando máscaras con atributos de Tlaloc (Saville 1899: 356). En San José Mogote, bajo el piso del Templo 35, el Elemento 96 conforma una escena con una efigie con rasgos de Tlaloc la cual sostiene un rayo en la mano acostada sobre una caja, en cuyo interior se encontraron restos de una codorniz y un plato con una efigie, a su vez, todo ello rodeado por cuatro efigies con adornos faciales del dios de la lluvia (ver Marcus y Flannery 1994: 71; Urcid 2009).
} 
Así, la noción de Cociyo como eje del mundo también tiene similitud con la visión del cosmos y el papel de Tlaloc entre los Aztecas, junto con sus cuatro servidores, los Tlaloques (Marcus 1983c: 345; Sellen 2002: 6). En casos del Centro de México, cada montaña o sierra alta es un dios, a su vez compañero menor de Tlaloc, responsable de engendrar nubes, deshacerlas en agua, y provocar el flujo de arroyos y ríos, por lo que aquellos que vivían cerca de estos montes proveedores, los adoraban llevándoles ofrendas (Torquemada 1976, t. 3, lib. VI, cap. 23: 77). Esta idea se comparte en muchas poblaciones a lo largo y ancho del territorio mesoamericano, donde cientos de sitios arqueológicos pero también comunidades contemporáneas, se asentaron sobre montañas, o cerca de ellas, consideradas sagradas, recipientes y generadores de lluvia, de dónde emanan ríos y manantiales (López Austin 1973: 62; Broda et al. 2001; Sahagún 1956, lib. XI, cap. 12, t. 3: 344; Torquemada 1976, t. 3, lib. VI, cap. 23: 77-78).

Es así como el concepto del altepetl resulta relevante. En el momento de contacto con los europeos, en el siglo XVI, el difrasismo en lengua náhuatl «agua-cerro» se usó frecuentemente de manera gráfica y lingüística para indicar el nombre de algún «pueblo» o «ciudad» (Sahagún 1956, lib. XI, cap. 12: 344-345) ${ }^{11}$. Dicha convención gráfica tiene antecedentes en tiempos más antiguos y en varias culturas. En el caso de la cultura visual zapoteca, numerosos ejemplos de la arqueología de Oaxaca, desde el Preclásico Tardío (200 a.C.- 200 d.C.), muestran un motivo de pirámide del cual frecuentemente salen plantas (o maíz) constituyendo así el símbolo del «lugar de» y por extensión, de la montaña sagrada (Markens 2011: 519, 2013). Coincidiendo con estas imágenes, existen registros de vasijas efigie Cociyo encima de este símbolo (ver Figura 2b) lo cual concuerda con el relato antes mencionado del Viejo Rayo del Fuego quien «gobernaba» las fuerzas naturales desde la cima del cerro. Sería también interesante investigar si en alguna comunidad zapoteca existe un término similar al de agua-cerro (nisa-tani) que refleje la misma idea de «pueblo» o «asentamiento».

Cabe decir que en el repertorio visual de la cultura zapoteca hasta ahora no es concluyente un glifo «de cerro» que haya sido usado topónimo de Monte Albán. No obstante, para Gordon Whittaker (1980: 150), un motivo piramidal en particular, en cuyo interior existen líneas diagonales y dos puntos, presente en las llamadas Lápidas de Conquista y otros monumentos y el cual se puede traducir como el «cerro de joyas preciosas», debió ser el nombre original del sitio, algo similar a Dhanhya'gach, en idioma zapoteco, o «Monte de las Joyas». Esta idea coincide con el nombre Cerro de Jade o la glosa en náhuatl «Chalchiuhtepetl» que identifican a una de las cimas del cerro así representada en el Lienzo de Xoxocotlan (Whittaker 1980: 150) (Figura 13). Es interesante que los chalchihuites o piedras verdes (como el jade) suelan asociarse con agua o elementos acuíferos (Miller y Taube 1993: 102) ${ }^{12}$. Asimismo, se-

${ }^{11}$ Sahagún (1956, lib. XI, cap. 12, t. 3: 344-345) mencionó que para los pueblos del Centro de México, los ríos salen del Tlalocan, «un paraíso terrenal» y los montes están sobre él como si fueran «vasos grandes de agua, o como casas llenas de agua», por lo que a los pueblos llaman altepetl, «monte de agua». Tlaloc y Chalchiuhtlicue son los señores dueños y custodios de estas aguas terrenales quienes también habitaban al interior de los cerros, en sitios de eterna primavera, donde también se encuentran todos los animales y plantas que alimentaban a los humanos (López Austin 1973: 62). El mural titulado «Tlalocan» en el palacio de Tepantitla de Teotihuacan, ilustra claramente el cerro donde emana agua y dónde los ancestros y seres del Otro Mundo habitan con alegría, diversión, abundancia y gozo, similar a un paraíso.

${ }^{12}$ En las culturas de Oaxaca y del Centro de México para tiempos del Postclásico, Chalchiuhtlicue o la Diosa de la Falda de Jade, se asociaba con las aguas terrestres vivas, que fluyen, señora nutricia y de sustentos (Rossell y Oje- 
gún relatos en la memoria de Oaxaca de hace algunas décadas, el nombre de «Monte Albán» es probablemente una derivación de «Tanibaana» o «Danibaan», donde tani o dani significa «cerro» y «baana» proviene de nabaana, «monte sagrado» (Cruz 1946: 163) ${ }^{13}$.

Así, la idea de Monte Albán como Montaña Sagrada o un altepetl (como Scarborough también sugirió con Tikal) merece atención, tal y como otros autores ya han señalado. Por ejemplo antes que un estado militar, la evidencia arqueológica apunta a Monte Albán como un centro político y religioso cuya fuerza se basaba en el simbolismo de la montaña sagrada, el axis mundi, siendo la plaza principal, visible desde partes remotas de los valles centrales, el escenario para la comunión de nobles y comuneros, partícipes de grandes ceremonias rituales, promoviendo a su vez la continuidad del cosmos y el poder de los gobernantes (Joyce 2004, 2010). Asimismo, las numerosas tumbas halladas en el sitio aluden a las cuevas que naturalmente yacen

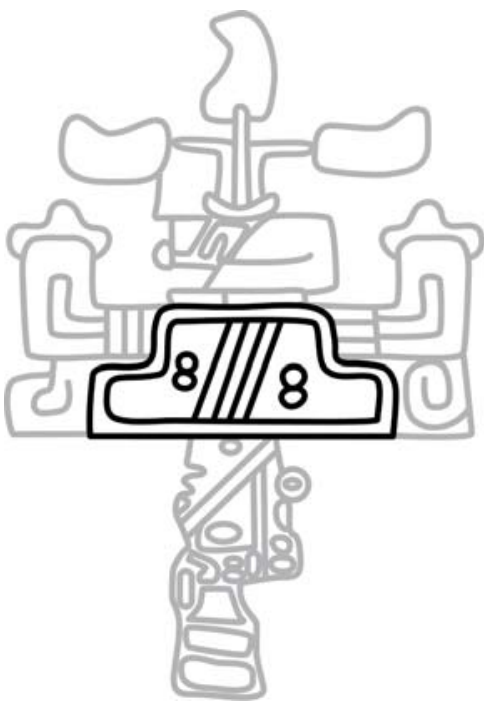

Figura 13. Topónimo de Monte Albán propuesto por Whitakker (dibujo a partir de García Moll et al. 1986) en las montañas, siendo éstas entradas al Otro Mundo y haciendo de las elevaciones topográficas lugares sagrados en conjunto, coincidiendo así con la noción pan-mesoamericana (González Licón 2015). No sólo la existencia de tumbas, pero también su misma construcción reconstruye los actos primordiales de los dioses al modelar con tierra este «gran lagarto terrestre» (pénne en zapoteco), usando lodo y estuco para recrear la textura de las cuevas, y formando un espacio rectangular, similar a la faz cuadrilátera de la Tierra, haciendo así de Monte Albán un cerro sagrado hecho por las manos de los hombres, reproduciendo así los actos de creación a partir de la tierra y huesos de los ancestros, y convirtiendo su interior en el refugio de dioses, germen de futuras creaciones y el lugar del tiempo ancestral (Magaloni 2010). Monte Albán es así un símil del Cerro Danush en la localidad de Macuilxochitl (Valle de Tlacolula), donde la comunidad lo considera un monte sagrado y al cual acuden con ofrendas y celebren en la cima, siendo esto una tradición con antecedentes prehispánicos así indicado por recientes hallazgos arqueológicos (Markens 2011, 2013).

Monte Albán parece así coincidir con tantos altepetl de Mesoamérica. Como se describió en este texto, es el cerro que contiene agua, por el cual escurre agua de lluvia en innumerables arroyos, que pasan por laderas y aluviones antes de llegar al río Atoyac. Monte Albán además de tener un manantial, aquí descrito, tiene una cueva conocida como «Cueva de Juan Rosa», ubicada en la ladera oriente, bajando de la

da Díaz 2003: 135). Es la diosa de lagos y arroyos, la que preside Nahui Atl o la era 4 Agua que, según la Leyenda de los Soles entre los aztecas, fue destruida por inundación (Miller y Taube1993: 60). Aparece en la página 11 del Códice Borgia, con su vestido verde, ricamente ataviada de joyas, y una nariguera de serpiente aludiendo al agua que corre.

${ }^{13}$ La partícula baan también parece relacionarse con «tumba», como un lugar de descanso, sugiriendo así a Monte Albán como una necrópolis (Whittaker 1980: 148). 
Plaza Principal, por la vereda que va al cerro del Mogollito (Jansen et al. 2012). Las cuevas son conocidos accesos a las entrañas de la Tierra (y al Tlalocan en la visión del Centro de México) y por ende son también zonas húmedas por donde suelen brotar manantiales (McCafferty y McCafferty 2008). Es coherente, como señala Joyce (2004), que en Monte Albán, un cerro visible a decenas de kilómetros, se fundara un centro ceremonial de grandes dimensiones, como símbolo de una nueva identidad social, donde se practicaban ritos públicos y privados, y donde gobernantes, sacerdotes y gente común vivían y también fueron enterrados. El paisaje aquí está íntimamente relacionado con lo divino y es sagrado.

Monte Albán fue muy probablemente el mayor templo para adorar al Rayo, a Cociyo, la deidad responsable del agua de lluvia, indispensable para cientos de comunidades agrícolas en los Valles Centrales. Un ejemplo similar se puede encontrar entre los ayöök (mixes) de Oaxaca y Mëj Kopkam o Zempoaltepetl, el recinto sagrado por excelencia de la región, recipiente de ofrendas y sacrificios, protector y auxiliador de cualquier angustia y enfermedad, a la vez morada y existencia misma del supremo dios y héroe Kontoy (ver Reyes Gómez s/f; Rojas 2014). Kontoy, coincide también en su asociación con el Trueno. El difrasismo en ayöök änë-witsëk o «trueno-relámpago» indica la llegada de lluvias (Reyes Gómez, comunicación personal). Entre los ayöök, cuando el trueno suena se dice que es la risa de Kontoy, que anuncia lluvias. Su hermana, Tajëëw, es la serpiente y es el relámpago. Kontoy es similar así a Cociyo y también Tlaloc, quien en los códices del Grupo Borgia aparece sosteniendo la serpiente (de fuego), el relámpago.

En el Zempoaltepetl, en días propicios del calendario de 260 días, se pide a Kontoy y la Tierra por bienestar y sustento, por la lluvia, alimento, maíz, dinero, trabajo, salud y fertilidad (ver Rojas 2014). Similarmente, quizá hace dos mil años en Monte Albán, la gente de la región subió a él, con ofrendas hechas de maíz, algunas en número especial, con tepache y mezcal, flores, figuritas de barro, y con aves para sacrificar, siguiendo el consejo de los sabios sacerdotes y sus calendarios. Monte Albán bien pudo ser también la morada de Cociyo y también la divinidad en sí. Como sucede hoy en día entre los ayöök, Monte Albán, fue el escenario idóneo en contacto con las nubes para las peticiones y prácticas de respeto a la Tierra, el Rayo y la Lluvia.

Agradecimientos: Gracias la Universidad de Leiden, Países Bajos, por las facilidades otorgadas para realizar la investigación y el trabajo de campo que dieron origen a este texto, así como al Consorcio Internacional de la Investigación en Humanidades (Fate, Freedom and Prognostication. Strategies for Coping with the Future in East Asia and Europe) de la Universidad de Erlangen, Alemania, por el apoyo otorgado con lo cual fue posible finalizar este artículo. Gracias al Instituto Nacional de Antropología e Historia y la Dirección de la Zona Arqueológica de Monte Albán por los permisos concedidos para recorrer el sitio arqueológico. Gracias a la Arqlga. Denisse Arriaga y Miguel García, así como a Svenja Kerkhof, Tom Lovett, Nienke Verstraaten y Philippa Jorissen por su participación en el recorrido arqueológico. Gracias a Deltares y Arquinistas por el trabajo en conjunto en el desarrollo de los proyectos urbanos e hidrológicos. Gracias los dictaminadores anónimos cuyas sugerencias mejoraron el resultado final de este texto. Y gracias al Arq. Urbanista Nahuel Beccan Dávila por impulsar el proyecto de protección del patrimonio arqueológico en Monte Albán, así como de mejoramiento urbano, natural y social a sus alrededores. 


\section{Referencias}

Acosta, Jorge

1949 «El pectoral de jade de Monte Albán». Anales del Instituto Nacional de Antropología e Historia 3: 17-25.

BALsalobre, Gonzalo de

1953 «Relación auténtica de las idolatrías, supersticiones, vanas observaciones de los indios del Obispado de Oaxaca» [1656], en Tratado de las supersticiones, dioses, ritos, hechicerías y otras costumbres gentilicias de las razas aborígenes de México, vol. II, Francisco del Paso y Troncoso, ed., pp. 337-390. México: Fuente Cultural Navarro.

Blanton, Richard E.

1978 Monte Albán: Settlement Patterns at the Ancient Zapotec Capital. Nueva York: Academic Press.

Blanton, Richard, Gary Feinman, Stephen Kowalewski y Linda Nicholas

1999 Ancient Oaxaca. Cambridge: Cambridge University Press.

BrodA, Johanna, Stanislaw IwANiszewski e Ismael A. Montero GArcía (coords.)

2001 La montaña en el paisaje ritual. México: Universidad Autónoma de Puebla, UNAM, CONACULTA, INAH.

Caso, Alfonso

2002 «Las últimas exploraciones de Monte Albán» [1932], en Obras de Alfonso Caso, vol. 1, pp. 39-48. México: El Colegio Nacional.

CAso, Alfonso e Ignacio BernaL

2003 «Urnas de Oaxaca» [1952], en Obras de Alfonso Caso, vol. 3, pp. 159-222. México: El Colegio Nacional.

CAso Alfonso, Ignacio Bernal y Jorge Acosta

1967 La cerámica de Monte Albán. México: INAH.

Córdova, Juan de

1987 Vocabulario en lengua zapoteca [1578]. México: Ediciones Toledo, INAH.

Cruz, Wilfrido

1946 Oaxaca recóndita. México: Linotipográficos Beatriz Silva.

DoolitTle, William E.

1989 «Pocitos and Registros: Comments on Water Control Features at Hierve el Agua, Oaxaca». American Antiquity 54 (4): 841-847.

1990 Canal Irrigation in Prehistoric Mexico. Austin: University of Texas Press.

Drennan, Robert y Kent Flannery

1983 «The Growth of Site Hierarchies in the Valley of Oaxaca: Part II», en The Cloud People, Kent Flannery y Joyce Marcus, eds., pp. 65-71. Nueva York: Academic Press.

DuUrzaAm StedeliJK Waterbeheer OAXaca

2013-14 Proyecto desarrollado por agencias holandesas (Deltares, Arcadis y MAP Urban Strategies) y financiado por el gobierno del Estado, el municipio de la Ciudad de Oaxaca y Partners Voor Water. Documento en archivo de MAP Urban Strategies. 
Feinman, Gary y Linda M. Nicholas

1990 «At the Margins of the Monte Albán State: Settlement Patterns in the Ejutla Valley, Oaxaca, Mexico». Latin American Antiquity 1 (3): 216-246.

FLANNERY, Kent V.

1983 «Precolumbian Farming in the Valleys of Oaxaca, Nochixtlan, Tehuacan, and Cuicatlan: A Comparative Study», en The Cloud People, Kent Flannery y Joyce Marcus, eds., pp. 323-339. Nueva York: Academic Press.

FlanNERY, Kent V. y Joyce Marcus (eds.)

1983 The Cloud People. Nueva York: Academic Press.

Flores Granados, Fabio

2016 Apropiación cultural del paisaje sagrado en la época prehispánica: Hierve el Agua. Mérida: Centro Peninsular en Humanidades y en Ciencias Sociales, UNAM.

GÁNDARA, Manuel

2012 «A Short History of Theory in Mesoamerican Archaeology», en The Oxford Handbook of Mesoamerican Archaeology, Deborah L. Nichols y Christopher Pool, eds., pp. 87-121. Oxford: Oxford University Press.

García Moll, Roberto, Donald W. Patterson Brown y Marcus Winter

1986 Monumentos escultóricos de Monte Albán (Materialien zur allgemeinen und vergleichenden Archaologie). Munich: C.H. Beck.

GonZÁLEZ Licón, Ernesto

2015 «Procesiones en Oaxaca». Arqueología Mexicana 131: 42-47.

GoNZÁLEz PÉREZ, Damián

2012 «El complejo del Rayo en la tradición oral de los zapotecos del sur de Oaxaca», en Folklore y tradición oral en arqueología, América Malbarán y Enrique Torres, eds., vol. 1, pp. 321-343. México: Centro de Estudios Sociales y Universitarios Americanos.

Hewitt, William P., Marcus Winter y David Peterson

1987 «Salt Production at Hierve el Agua, Oaxaca». American Antiquity 52 (4): 799-816.

JANSEN, Maarten, Dante García e Iván Rivera

2012 «La identificación de Monte Albán en los códices mixtecos: nueva evidencia», en Monte Albán y la Memoria Mixteca, informe preliminar, Maarten Jansen, ed., pp. 6-22. Leiden: Leiden University.

JOYCE, Arthur

2004 «Sacred Space and Social Relation in the Valley of Oaxaca», en Mesoamerican Archaeology, Julia A. Hendon y Rosemary A. Joyce, eds., pp. 192-216. Malden: Blackwell Publishing.

2010 Mixtecs, Zapotecs, and Chatinos, Ancient peoples of Southern Mexico. Malden: Wiley-Blackwell.

KIRKBY, Anne V.T.

1973 The Use of Land and Water Resources in the Past and Present Valley of Oaxaca, Mexico. Memoirs of the Museum of Anthropology, number 5, vol. 1. Ann Arbor: University of Michigan.

Kowalewski, Stephen A.

1976 Prehispanic Settlement Patterns of Central Part of the Valley of Oaxaca, Mexico. Ann Arbor: University Microfilms. 
LeEs, Susan H.

1973 Socio-Political Aspects of Canal Irrigation in the Valley of Oaxaca, Mexico, Memoirs of the Museum of Anthropology, number 6, vol. 2. Ann Arbor: University of Michigan.

LIND, Michael y Javier URCID

2010 The Lords of Lambityeco: Political Evolution in the Valley of Oaxaca during the Xoo Phase. Boulder: University Press of Colorado.

LóPEZ Austin, Alfredo

1973 Hombre-Dios. Religión y política en el mundo náhuatl. México: Instituto de Investigaciones Históricas, UNAM.

LOVETT, Tom

2015 Monte Albán: Built with Water in Mind. Tesis inédita de BA. University College Londres.

Magaloni KerPel, Diana

2010 «The Hidden Aesthetic of Red in the Painted Tombs of Oaxaca». RES: Anthropology and Aesthetics 57/58: 55-74.

Marcus, Joyce

1983a «The Conquest Slabs of Building J, Monte Albán», en The Cloud People, Kent Flannery y Joyce Marcus, eds, pp. 106-108. Nueva York: Academic Press.

1983 « «Rethinking the Zapotec Urn», en The Cloud People, Kent Flannery y Joyce Marcus, eds., pp. 144-152. Nueva York: Academic Press.

1983c «Zapotec Religion», en The Cloud People, Kent Flannery y Joyce Marcus, eds., pp. 345-351. Nueva York: Academic Press.

2006 «The Roles of Ritual and Technology in Mesoamerican Water Management», en Agricultural Strategies, Joyce Marcus y Charles Stanish, eds., pp. 221-254. Los Angeles: Cotsen Institute of Archaeology.

2008 Monte Albán. México: Colmex - Fideicomiso Historia de las Américas - FCE.

Marcus, Joyce y Kent FlanNery

1994 «Ancient Zapotec Ritual and Religion: An Application of the Direct Historical Approach», en The Ancient Mind: Elements of Cognitive Archaeology, Colin Renfrew y Ezra B. Zubrow, eds., pp. 55-74. Cambridge: University of Cambridge Press.

1996 Zapotec Civilization. Londres: Thames and Hudson.

MARKENS, Robert

2011 «La transición del Clásico al Postclásico en el Valle de Oaxaca: causas y consecuencias de una crisis política», en Memoria de la Quinta Mesa Redonda de Monte Albán, Nelly Robles y Ángel I. Rivera, eds., pp. 489-530. México: CONACULTA, INAH.

2013 «El jaguar y la montaña sagrada: la base del poder en la civilización zapoteca, Valle de Oaxaca», en El jaguar en Oaxaca, A. Aquino, V. de la Cruz, M. Briones-Salas, A. Sánchez y M. Huerta, eds., pp. 196-201. Oaxaca de Juárez: Gobierno del Estado de Oaxaca, Secretaría de las Culturas y Artes de Oaxaca, INAH, UABJO.

Martinez Ruíz, José Luis y Daniel Murillo LiceA

2009 «Segunda parte», en Cultura hidráulica y simbolismo mesoamericano del agua en el México prehispánico, pp. 155-274. Jiutepec: IMTA/CIESAS. 
Mason, Roger D., Dennis E. Lewarch, Michael J. O'Brien y James A. Neely

1977 «An Archaeological Survey of the Xoxocotlan Piedmont, Oaxaca, Mexico». American Antiquity 42 (4): 567-575.

McCafferty, Sharisse D. y Geoffrey G. McCAFFERTY

2008 «Back to the Womb: Caves, Sweatbaths and Sacred Water in Ancient Mesoamerica», en Flowing through Time: Exploring Archaeology through Humans and their Aquatic Environment, Larry Steinbrenner, Beau Cripps, Metaxia Georgopoulos y Jim Carr, eds., pp. 26-33. Calgary: The Archaeological Association of the University of Calgary.

MiLler, Mary Ellen y Karl A. TAubE

1993 An Illustrated Dictionary of the Gods and Symbols of Ancient Mexico and the Maya. Londres: Thames and Hudson.

NaVArro, Laura y Joaquín Arroyo-CABrales

2013 «Bats in Ancient Mesoamerica», en The Archaeology of Mesoamerican Animals, Christopher M. Götz y Kitty F. Emery, eds., pp. 583-605. Atlanta: Lockwood.

NeELY, James A.

1967 «Organización hidráulica y sistemas de irrigación pre-históricos en el Valle de Oaxaca». Boletín del Instituto Nacional de Antropología e Historia 27: 15-17.

1972 «Prehistoric Domestic Water Supplies and Irrigation Systems at Monte Albán, Oaxaca, Mexico», ponencia presentada en el $37^{\text {th }}$ Annual Meeting of the Society for American Archaeology, Archivo Instituto Welte, pp. 1-15.

NeELY, James A. y Michael J. O’BrIEN

1973 «Irrigation and Settlement Nucleations at Monte Albán: A Test of Models», ponencia presentada en el $38^{\text {th }}$ Annual Meeting of the Society for American Archaeology, archive, Instituto Welte, pp. 1-19.

O’brien, Michael J., Denis E. Lewarch, Roger D. Mason y James A. Neely

1980 «Functional Analysis of Water Control Features at Monte Albán, Oaxaca, Mexico». World Archaeology 11 (3): 342-355.

O’brien, Michael J., Roger D. Mason, Denis E. Lewarch, y James A. Neely

1982 A Late Formative Irrigation Settlement below Monte Albán. Austin: University of Texas Press.

PACHECO ArIas, Leobardo

2014 «Urnas de Atzompa. Manufactura e imaginería zapoteca». Arqueología Mexicana 126: 56-59.

PADDOCK, John (ed.)

1966 Ancient Oaxaca. Stanford: Stanford University Press.

ReYes Gómez, Juan Carlos

s/f Kontoy y Tajëëw: los dioses padre y madre de los ayuuk. Manuscrito en prensa, Gobierno del Estado de Oaxaca, Oaxaca.

Rojas Martínez Gracida, Araceli

2014 El tiempo y la sabiduría: un calendario sagrado entre los ayöök de Oaxaca. Oaxaca: CONACULTA.

2015 Informe del recorrido en escurrimientos, arroyos y manantiales de Monte Albán (verano 2014). Manuscrito en archivo técnico del INAH, México. 
Rojas Martínez Gracida, Araceli y Nahuel Beccan Dávila

E.p. «El agua que escurre de Monte Albán: uso de arroyos y espacios públicos como estrategia en la protección del patrimonio arqueológico». Memorias del Primer Congreso de Patrimonio Cultural de Oaxaca, Ciudad de Oaxaca, diciembre 2016.

Rojas Rabiela, Teresa

2009 «Las obras hidráulicas en las épocas prehispánica y colonial», en Semblanza histórica del agua en México, pp. 9-25. México: CONAGUA.

Rossell, Cecilia y María de los Ángeles OJeda DíAz

2003 Las mujeres y sus diosas en los códices prehispánicos de Oaxaca. México: CIESAS/Miguel Ángel Porrúa.

SAHAGún, fray Bernardino de

1956 Historia general de las cosas de Nueva España [1569], 4 tomos. México: Porrúa.

SANSORES, Francisco Javier

1992 «El control del agua en Monte Albán, nuevas evidencias». Cuadernos de Arquitectura Mesoamericana 18:19-28.

SAVILLE, Marshall

1899 «Exploration of Zapotecan Tombs in Southern Mexico». American Anthropologist 8 (1): $350-362$.

SCARBOROUGH, Vernon

1998 «Ecology and Ritual: Water Management and the Maya». Latin American Antiquity 9 (2): $135-159$.

SELLEN, Adam

2002 «Storm-God Impersonators from Ancient Oaxaca». Ancient Oaxaca 13: 3-19.

2005 Catalogue of Zapotec Effigy Vessels. Base de datos y dibujos de vasijas efigie zapotecas en el sitio http://research.famsi.org/zapotec/zapotec.html (con acceso en enero de 2018).

2007 El cielo compartido. Deidades y ancestros en las vasijas efigie zapotecas. México: UNAM.

2011 «Sowing the Blood with Maize». Ancient Mesoamerica 22 (1): 71-89.

SPENCER, Charles

2003 «War and Early State Formation in Oaxaca, Mexico». Proceedings of the National Academy of Sciences of the United States of America 100 (20): 11.185-11.187.

Torquemada, fray Juan de

1976 Monarquía Indiana [1615], 7 tomos. México: Instituto de Investigaciones Históricas. UNAM.

URCID, Javier

1998 «Codices on Stone: The Genesis of Writing in Ancient Oaxaca». Journal of Hispanic Literatures 13: 7-16.

2009 «Personajes enmascarados. El rayo, el trueno y la lluvia en Oaxaca». Arqueología Mexicana 96: 30-34.

2011a «Los oráculos y la guerra: el papel de las narrativas pictóricas en el desarrollo temprano de Monte Albán (500 a.C.-200 d.C.)», en Monte Albán en la encrucijada regional y disciplinaria, Nelly M. Robles y Ángel I. Rivera, eds., pp. 163-237. Memoria de la Quinta Mesa Redonda de Monte Albán. México: CONACULTA, INAH. 
2011 b «The Written Surface as a Cultural Code. A Comparative Perspective of Scribal Traditions from Southwestern Mesoamerica», en Their Way of Writing: Scripts, Signs, and Pictographs in Pre-Columbian America, Elizabeth Hill Boone y Gary Urton, eds., pp. 111-148. Washington D.C.: Dumbarton Oaks.

WhITTAKER, Gordon

1980 The Hieroglyphs of Monte Albán. Tesis de doctorado. Yale University.

WINTER, Marcus

1992 Oaxaca. The Archaeological Record. México: Minutiae Mexicana.

2009 «La religión, el poder y las bases de la complejidad social en Oaxaca prehispánica», en Bases de la complejidad social en Oaxaca. Memoria de la Cuarta Mesa Redonda de Monte Albán, Nelly Robles, ed., pp. 503-527. México: INAH.

2011 «Social Memory and the Origins of Monte Albán». Ancient Mesoamerica 22 (2): 393-409.

WitTFOGEL, Karl

1957 Oriental Despotism. New Haven: Yale University Press.

WoLf, Eric

1959 Sons of the Shaking Earth. Chicago: University of Chicago Press. 